\title{
Simple and Sensitive Multi-Components Detection Using Synthetic Nitrogen-Doped Carbon Dots Based on Soluble Starch
}

Yuanyuan Hu ( $\sim$ huyuanyuan@ctgu.edu.cn )

China Three Gorges University https://orcid.org/0000-0002-5654-3253

Wenxuan Ji

China Three Gorges University

Jinjuan Qiao

Weifang Medical University

Heng Li

Weifang Medical University

Yun Zhang

Xinxiang Medical University

Jun Luo

China Three Gorges University

\section{Research Article}

Keywords: Carbon dots, Metal ions, Ascorbic acid, Sensor, Bioimaging

Posted Date: April 12th, 2021

DOI: https://doi.org/10.21203/rs.3.rs-363653/v1

License: (1) This work is licensed under a Creative Commons Attribution 4.0 International License.

Read Full License 


\section{Simple and sensitive multi-components detection using synthetic nitrogen-doped carbon dots based on soluble starch}

Yuanyuan $\mathrm{Hu}^{1,2 *}$, Wenxuan $\mathrm{Ji}^{1}$, Jinjuan Qiao ${ }^{3}$, Heng $\mathrm{Li}^{3}$, Yun Zhang ${ }^{4}$, Jun Luo ${ }^{*}$

\section{Author information}

${ }^{1}$ Medical College, China Three Gorges University, Yichang, 443002, China.

huyuanyuan@ctgu.edu.cn;1345496736@qq.com

${ }^{2}$ Third-grade Pharmacological Laboratory on Traditional Chinese Medicine (Approved by State Administration of Traditional Chinese Medicine of China, SATCM), China Three Gorges University, Yichang, 443002, China. huyuanyuan@ctgu.edu.cn.

3 Department of Medical Laboratory, Weifang Medical University, Weifang, 261053, China. qiaojj@wfmc.edu.cn; 5394746@qq.com

4 School of Laboratory Medicine, Xinxiang Medical University, Xinxiang, 453003, China. zhangyun0126@126.com

${ }^{5}$ The First College of Clinical Medical Science, China Three Gorges University, Yichang, 443003, China. 1j1988cby@126.com

* Corresponding authors:

Yuanyuan $\mathrm{Hu}$

huyuanyuan@ctgu.edu.cn

ponyhoo@gmail.com

ORCID iD: https://orcid.org/0000-0002-5654-3253

Jun Luo

1j1988cby@126.com 
ABSTRACT: Although carbon dots (CDs) as fluorescent sensors have been widely exploited, multi-component detection using CDs without tedious surface modification is always a challenging task. Here, two kinds of nitrogen-doped CDs (NCD-m and NCD-o) based on soluble starch (SS) as carbon source were prepared through one-pot hydrothermal process using m-phenylenediamine and o-phenylenediamine as nitrogenous dopant respectively. Through fluorescence "on-off" mechanism of CDs, NCD-m and NCD-o could be used as a fluorescence sensor for detection of $\mathrm{Fe}^{3+}$ and $\mathrm{Ag}^{+}$with LOD of 0.25 and $0.5 \mu \mathrm{M}$, respectively. Additionally, NCD-m could be used for indirect detection of ascorbic acid (AA) with LOD of $5 \mu \mathrm{M}$. Moreover, fluorescence intensity of NCD-m also exhibited the sensitivity to $\mathrm{pH}$ change from 2 to 13 . More importantly, Both NCD-m and NCD-o had potential application for analysis of complicated real samples such as tap water, Vitamin $\mathrm{C}$ tablets and orange juice. Ultimately, the small size of NCD-m could contribute to reinforcing intracellular endocytosis, which allowed them to be used for bacteria imaging.

Key words: Carbon dots. Metal ions. Ascorbic acid. Sensor. Bioimaging

\section{Introduction}

Metal ions are essential for versatile physiological processes. Dysregulation of specific metal ion levels in living organisms is known to have an adverse effect on normal biological events. Owing to the pathophysiological significance of metal ions, sensitive and selective methods to detect these ions in biological systems, environment, food and water are in high demand. Fluorescent sensors have attracted increasing attention for detection of metal ions in vitro and vivo, owing to their rapidity, simplicity, high selectivity and sensitivity, and possibility for real-time monitoring [1,2]. Generally, most widely used fluorescent sensors include organic dyes [3], semiconductor quantum dots (QD)[4], fluorescent metal nanoclusters[5] and fluorescent metal organic frameworks[6], etc. However, their defects such as photo instability, complex 
equipment and treatment processes, high costs, environmental unfriendliness and cytotoxicity also hinder their practical applications.

As a new class of zero-dimensional spherical nanomaterials in carbon family, carbon dots (CDs) have attracted wide attention due to their merits of multiple optical and electrochemical properties, chemical stability, photostability, biocompatibility, easy functionalization and low toxicity. Therefore, CDs are applied in the fields of sensing, electrochemistry, nano-catalysis, and bioimaging, etc. [7-9] However, there is still a mutual defect due to lack of sufficient theoretical and experimental knowledge on fluorescence origins in CDs, which is low quantum yields (QYs) among most asprepared CDs and significantly limits the development and application of CDs as fluorescence materials [10,11]. By far, one of the most striking ways is the doping of atoms (like N, S, P and B) [12]. Plenty of works have been focused on the N or S- doped CDs. In the process of $\mathrm{N}$ doping, $\pi$-conjugate domain of pyridone-like structures formed by condensation reaction are most likely cause of high QYs [13].

Some metal ions $\left(\mathrm{Fe}^{3+}, \mathrm{Ag}^{+}, \mathrm{Mo}^{6+}, \mathrm{Cr}^{6+}, \mathrm{Hg}^{2+}, \mathrm{Pb}^{2+}, \mathrm{Cu}^{2+}\right.$, etc. $)$ can interact with functional groups on the surface of some CDs to change their fluorescence properties. For example, $\mathrm{Fe}^{3+}$ leads to fluorescence quenching of N-doped CDs (NCDs) [14-20]. And $\mathrm{Ag}{ }^{+}$causes fluorescence quenching of NCDs and N-other atom co-doped CDs [21-24]. Moreover, fluorescence of some NCDs is able to be effectively retained when $\mathrm{Fe}^{3+}$ is reduced to $\mathrm{Fe}^{2+}$ by reductants such as ascorbic acid (AA) $[25,26]$. Therefore, NCDs as fluorescence sensors of metal ions and other analytes have been widely developed.

In this study, two kinds of soluble starch-derived NCDs (NCD-m and NCD-o) were doped by m-phenylenediamine and o-phenylenediamine respectively. $\mathrm{Fe}^{3+}$ and $\mathrm{Ag}{ }^{+}$ ions were effectively able to quench fluorescence of NCD-m and NCD-o respectively. Therefore, fluorescence sensors based on NCD-m and NCD-o for detecting $\mathrm{Fe}^{3+}$ and $\mathrm{Ag}^{+}$ions were respectively established with acceptable detection limits and linear ranges. Additionally, NCD-m could be used indirectly to detect ascorbic acid (AA) on the basis of reduction of $\mathrm{Fe}^{3+}$ to $\mathrm{Fe}^{2+}$ by AA. More importantly, these sensors based on 
as-prepared NCDs could be applied to multi-components detection of $\mathrm{Ag}^{+}, \mathrm{Fe}^{3+}$ and AA in real samples. Moreover, fluorescence intensity of NCD-m was sensitive to $\mathrm{pH}$ change, which makes them had a potential as pH sensor. Finally, NCD-m showed their excellent biocompatibility, along with their optical merits, strongly reinforced their applicability potential as bacteria (E. coli) imaging agent.

\section{Materials and methods}

\subsection{Chemicals}

M-phenylenediamine (MPD), o-phenylenediamine (OPD), $\mathrm{AgNO}_{3}, \mathrm{CaCl}_{2}, \mathrm{CdCl}_{2}$, $\mathrm{CoCl}_{2}, \mathrm{CuCl}_{2}, \mathrm{FeCl}_{3}, \mathrm{FeCl}_{2}, \mathrm{Hg}\left(\mathrm{NO}_{3}\right)_{2}, \mathrm{Mg}(\mathrm{OAc})_{2}, \mathrm{MnCl}_{2}, \mathrm{NiCl}_{2}, \mathrm{~Pb}\left(\mathrm{NO}_{3}\right)_{2}, \mathrm{Zn}$ $(\mathrm{OAc})_{2}, \mathrm{Na}_{2} \mathrm{SO}_{4}, \mathrm{Na}_{2} \mathrm{SO}_{3}, \mathrm{Na}_{2} \mathrm{CO}_{3}, \mathrm{NaNO}_{3}$ and ascorbic acid (AA) were purchased from Aladin Ltd. (Shanghai, China). Additionally, Vitamin C (ascorbic acid) assay kit (colorimetric method) was purchased from Jiancheng Bioengineering Institute (Nanjing, China) while Vitamin C tablets were purchased from a local pharmacy. Finally, soluble starch (SS) and orange juice were purchased from a local supermarket.

\subsection{Instrumentation}

JEM-F200 transmission electron microscope (TEM) (JEOL, Japan) was used to obtain morphological images of as-prepared NCDs. In addition, F-4600 spectrofluorometer (Hitachi, Japan) was used to measure fluorescence intensity and steady-state emission spectra. UV-2600 spectrophotometer (Shimadzu, Japan) was applied to gather UVVisible absorption spectra. Moreover, FT-IR spectra were obtained using KBr pellets on IR Affinity-1S FT-IR spectrophotometer (Shimadzu, Japan) to identify functional organic groups within a spectral window of $650-4000 \mathrm{~cm}^{-1}$. X-ray diffraction pattern was measured on AXS-D8 X-ray diffractometer (Bruker, Germany). Finally, bacteria imaging was performed by A1+/A1R+ laser scanning confocal microscope (Nikon, Japan). 


\subsection{Synthesis of NCDs}

Nitrogen-doped carbon dots (NCDs) were prepared using one-pot hydrothermal method. In brief, SS $(0.25 \mathrm{~g})$ was dissolved in $\mathrm{ddH}_{2} \mathrm{O}(50 \mathrm{ml})$ with MPD and OPD $(0.5 \mathrm{~g})$ respectively before transferring the mixture into a Teflon-lined autoclave and heating at $160{ }^{\circ} \mathrm{C}$ for $10 \mathrm{~h}$. After cooling down to room temperature, the supernatant was collected by removing large insoluble dots through centrifugation at 10,000 rpm for $30 \mathrm{~min}$ and then filtered using $0.22 \mu \mathrm{m}$ syringe filters. Subsequently, the preprocessed supernatant was dialyzed against $\mathrm{ddH}_{2} \mathrm{O}$ for $24 \mathrm{~h}$ and then lyophilized. Finally, the residues of NCDs powder were stored in $4^{\circ} \mathrm{C}$ until use. NCDs prepared from SS and MPD were named NCD-m while those obtained using SS and OPD were labelled NCD-o.

\subsection{Fluorescence detection of $\mathrm{Fe}^{3+}, \mathrm{Ag}^{+}$and $\mathrm{AA}$}

In order to detect $\mathrm{Fe}^{3+}$ and $\mathrm{Ag}^{+}, \mathrm{NCD}-\mathrm{m}$ and NCD-o $(0.2 \mathrm{mg} / \mathrm{mL})$ were respectively mixed with $\mathrm{Fe}^{3+}$ and $\mathrm{Ag}^{+}$at various final concentrations ranging from $0 \mu \mathrm{M}$ to 1000 $\mu \mathrm{M}(0,0.125,0.25,0.5,1,2,3$, $4,5,10,15,20,25,50,75,100,125,150,250,350,450,550,650,750,850$ and $1000 \mu \mathrm{M})$ in 2 $\mathrm{mL} \mathrm{ddH} \mathrm{H}_{2} \mathrm{O}$. Their fluorescence spectra were collected at room temperature. Fluorescence quenching of as-prepared NCDs follows Stern-Volmer equation [27]. Therefore, Relative Fluorescence Intensity $\left(F_{0} / F-1\right)$ was calculated to be the signal output value where $F_{0}$ and $F$ respectively represented fluorescence intensity at $\mathrm{Ex}=445 \mathrm{~nm}$ of NCD-m or $405 \mathrm{~nm}$ of NCD-o in the absence and presence of $\mathrm{Fe}^{3+}$ or $\mathrm{Ag}^{+}$.

In order to detect $\mathrm{AA}, \mathrm{Fe}^{3+}(500 \mu \mathrm{M})$ were mixed with $\mathrm{AA}$ at various final concentrations ranging from $0 \mu \mathrm{M}$ to $850 \mu \mathrm{M}(0,0.125,0.25,0.5,1,2,3$, $4,5,10,15,20,25,50,75,100,125,150,250,350,450,550,650,750$ and $850 \mu \mathrm{M})$ in $2 \mathrm{~mL}$ HAc-NaAc buffer $(20 \mathrm{mM}, \mathrm{pH}=3.0)$. Afterwards, NCD-m $(0.2 \mathrm{mg} / \mathrm{mL})$ were added into $\mathrm{Fe}^{3+}+\mathrm{AA}$ and their fluorescence spectra were collected at room temperature. Relative Fluorescence Intensity $\left(F / F_{0}\right)$ was calculated to be the signal output 
value where $F_{0}$ and $F$ respectively represented fluorescence intensity at Ex=445 nm of $\mathrm{NCD}-\mathrm{m}$ in the absence and presence of $\mathrm{Fe}^{3+}+\mathrm{AA}$.

In addition, the selectivity of as-prepared NCDs towards $\mathrm{Fe}^{3+}, \mathrm{Ag}^{+}$and $\mathrm{AA}$ was examined by adding different interferents under the same test conditions. (Concentration of NCD-m and NCD-o was $0.2 \mathrm{mg} / \mathrm{mL}$; Concentration of $\mathrm{Fe}^{3+}, \mathrm{Ag}^{+}$, AA and all interferents was $500 \mu \mathrm{M})$.

The reaction time in each step of the above experiments was $10 \mathrm{~min}$.

\subsection{Fluorescence detection of $\mathrm{Fe}^{3+}, \mathrm{Ag}^{+}$and $\mathrm{AA}$ in real samples}

In order to detect $\mathrm{Fe}^{3+}$ and $\mathrm{Ag}^{+}$in real samples, tap water obtained from our lab was analyzed using the present methods. The water samples were spiked with $\mathrm{Fe}^{3+} / \mathrm{Ag}^{+}$at different concentrations without any pretreatment.

On the other hand, VC tablet sample was prepared by dissolving one Vitamin C Tablet

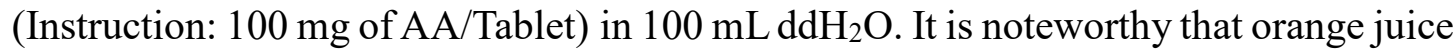
(Instruction: $2 \mathrm{mg}$ of AA/100 mL) did not need any pretreatment. VC tablet sample and orange juice were spiked with AA at different concentrations. Testing and data processing were based on the present method.

\subsection{Bacteria imaging}

Escherichia coli (E. coli DH5 $\alpha$ ) bacteria were grown overnight at $37^{\circ} \mathrm{C}$ in Luria-Bertani medium. Subsequently, $1 \mathrm{ml}$ bacterial culture medium were placed into $2 \mathrm{~mL}$ Ep tube. The bacteria were collected by removing the medium through centrifugation at 10,000 rpm for $1 \mathrm{~min}$ and then washed twice using $\mathrm{ddH}_{2} \mathrm{O}$. The purified bacteria were incubated with NCD-m $(0.2 \mathrm{mg} / \mathrm{mL})$ at $37^{\circ} \mathrm{C}$ for $12 \mathrm{~h}$ in $500 \mu \mathrm{L}$ mixed solution $(\mathrm{v} / \mathrm{v}$ phosphate buffered solution: DMSO = 3:2). Afterwards, the bacteria were collected by removing the unbound NCD-m in supernatant through centrifugation at 10,000 rpm for $1 \mathrm{~min}$ and then washed twice using $\mathrm{ddH}_{2} \mathrm{O}$. Finally, bacteria imaging was performed using confocal fluorescence microscopy. 


\section{Results and Discussion}

\subsection{Characterization of NCDs}

Morphology of as-prepared NCDs were observed using Transmission electron microscopy (TEM). Fig. 1a and b show that both NCD-m and NCD-o had good uniformity and dispersibility, and the average particle size was $5 \pm 0.5 \mathrm{~nm}$. HRTEM images of NCD-m and NCD-o are shown in the insets of Fig. 1a and b, indicating that lattice spacing was $0.2 \mathrm{~nm}$, which was consistent with the (100) plane spacing of $\mathrm{sp}^{2}$ carbon $[28,29]$. Additionally, Fig. $1 \mathrm{c}$ indicates that the measured XRD pattern of NCD-m and NCD-o demonstrated the similar peaks centered at $2 \theta=22.3 \AA$, which was corresponding to a representative graphite structure [30]. Moreover, functional groups on the surface of as-prepared NCDs were identified using FT-IR spectra. NCD-m and NCD-o had similar FT-IR spectra as demonstrated in Fig. 1d. The broad band centered at $3,271 \mathrm{~cm}^{-1}$ was contributed by the stretching vibrations of $\mathrm{O}-\mathrm{H} / \mathrm{N}-\mathrm{H}$. On the other hand, the absorption at $2,925 \mathrm{~cm}^{-1}$ was attributed to the stretching vibration of $\mathrm{C}-\mathrm{H}$ due to hydrogen-atom-rich periphery of benzene ring structure to be retained. Additionally, the peak at $1,633 \mathrm{~cm}^{-1}$ belonged to $\mathrm{C}=\mathrm{C}$ stretching vibration of polycyclic aromatic hydrocarbons. Moreover, the bands at 1,330 and $1,014 \mathrm{~cm}^{-1}$ were attributed to the C-N(amine) and C-O (alcohols or phenols) stretching vibration, respectively. The above results indicated that NCDs with the lattice structures were successfully synthesized and possessed many chemical groups on the surface including hydroxyl, carboxyl and amine groups.

\subsection{Optical properties of NCDs}

Fluorescence and UV-vis spectra were employed to investigate the typical optical properties of as-prepared NCDs. As shown in the insets of Fig. 2a and b, NCD-m and NCD-o respectively emitted green and yellow fluorescence under $365 \mathrm{~nm}$ UV lamp. Fig. S1a and $\mathrm{b}$ show that an increase in excitation wavelength resulted in a gradual and slight redshift in emission wavelength of both NCD-m and NCD-o. In addition, emission intensity changed according to variations in excitation intensity in certain 
ranges. Maximum excitation wavelength for NCD-m and NCD-o was $445 \mathrm{~nm}$ and 405 $\mathrm{nm}$ respectively while corresponding emission wavelength was $527 \mathrm{~nm}$ and $561 \mathrm{~nm}$ respectively. Evidently, both NCD-m and NCD-o exhibited the excitation-dependent emission behavior, which is ascribed to different band gaps from various defect/surface states of CDs [31]. Moreover, NCD-m and NCD-o displayed different UV-vis absorption as illustrated in Fig. 2. UV-vis spectrum of NCD-m indicated an absorption peak at $290 \mathrm{~nm}$, corresponding to $\mathrm{n}-\pi^{*}$ electronic transition. UV-vis absorption spectrum of NCD-o had three characteristic peaks at 237, 257 and $282 \mathrm{~nm}$ in UV region and a broad peak at $416 \mathrm{~nm}$ in visible region. The two absorption peaks located at $237 \mathrm{~nm}$ and $257 \mathrm{~nm}$ were attributed to $\pi-\pi^{*}$ transitions of aromatic $\mathrm{sp}^{2}$ domain from the carbon core typically, and the other two absorption peaks located at $282 \mathrm{~nm}$ and $416 \mathrm{~nm}$ were assigned to $\mathrm{n}-\pi *$ transitions of $\mathrm{C}=\mathrm{N} / \mathrm{C}=\mathrm{O}$ and/or $\mathrm{C}-\mathrm{N}$ from surface moieties [32-34].

\subsection{Stability of NCDs}

Stability of as-prepared NCDs is important to evaluate their practical applications in chemical and biological sensing. The effect of storage time, ionic strength and $\mathrm{pH}$ on stability of as-prepared NCDs was investigated. Fig. S2a shows that there was no significant change in fluorescence intensity of NCD-m and NCD-o aqueous solutions within 1 to 6 months of storage. As shown in Fig. S2b, fluorescence intensity of NCD-m decreased to some extent with an increase of ionic strength, indicating that high ionic strength leaded to the partial fluorescence quenching of NCD-m. Meanwhile, fluorescence intensity of NCD-o was stable in high salt solutions even when the concentration of $\mathrm{NaCl}$ was up to physiological ionic strength $(\sim 200 \mathrm{mM})$, indicating that NCD-o was able to resist comparatively high ionic strength. Moreover, fluorescence intensity of as-prepared NCDs was sensitive to $\mathrm{pH}$ variation. Fig. 3a and $\mathrm{c}$ indicate that fluorescence intensity of NCD-m gradually and significantly decreased with $\mathrm{pH}$ change from 2 to 13 . However, NCD-o exhibited a different sensitivity toward $\mathrm{pH}$ variation. Fig. $3 \mathrm{~b}$ and demonstrate that fluorescence intensity of NCD-o 
was comparatively stable under neutral conditions $(\mathrm{pH}=7)$ but significantly decreased under acidic $(\mathrm{pH}=6-2)$ and alkaline conditions $(\mathrm{pH}=8-13)$. Some researchers speculated that protonation-deprotonation occurring on the surface of these CDs with $\mathrm{pH}$ variation induced the changes in surface charges, resulting in $\mathrm{pH}$ dependence[3537]. Therefore, NCD-m might have a potential application of monitoring $\mathrm{pH}$ change in vitro or vivo. In addition, a neutral $\mathrm{pH}$ condition was important to the further application of NCD-o as fluorescence senor or bioimaging agent.

\subsection{Fluorescence response of NCDs to a variety of analytes}

19 kinds of analytes $\left(\mathrm{Ag}^{+}, \mathrm{Ca}^{2+}, \mathrm{Cd}^{2+}, \mathrm{Co}^{2+}, \mathrm{Cu}^{2+}, \mathrm{Fe}^{3+}, \mathrm{Fe}^{2+}, \mathrm{Hg}^{2+}, \mathrm{Mg}^{2+}, \mathrm{Mn}^{2+}\right.$, $\mathrm{Ni}^{2+}, \mathrm{Pb}^{2+}, \mathrm{Zn}^{2+}, \mathrm{SO}_{4}{ }^{2-}, \mathrm{SO}_{3}{ }^{2-}, \mathrm{CO}_{3}{ }^{2-}, \mathrm{NO}_{3}{ }^{-}, \mathrm{Cl}^{-}$and $\left.\mathrm{AA}\right)$ at a concentration of 500 $\mu \mathrm{M}$ were chosen to test the selectivity of as-prepared NCDs $(0.2 \mathrm{mg} / \mathrm{mL})$ as exhibited in Fig. 4. Compared with the other analytes, fluorescence of NCD-m and NCD-o was effectively quenched by $\mathrm{Fe}^{3+}$ and $\mathrm{Ag}^{+}$respectively. Therefore, NCD-m and NCD-o displayed obvious selectivity toward $\mathrm{Fe}^{3+}$ and $\mathrm{Ag}^{+}$respectively and this provided the study with a possibility of monitoring $\mathrm{Fe}^{3+}$ and $\mathrm{Ag}^{+}$through as-prepared NCDs. It was worth noting that $\mathrm{Fe}^{2+}$ could not effectively quench fluorescence of NCD-m, which provided a possible mean of detecting reducing agents those could reduce $\mathrm{Fe}^{3+}$ to $\mathrm{Fe}^{2+}$. Moreover, the responsive time of as-prepared NCDs toward $\mathrm{Fe}^{3+}$ and $\mathrm{Ag}^{+}$ was measured and the result was shown in Fig. S3, which indicates that the response of NCD-m toward $\mathrm{Fe}^{3+}$ was balanced within $5 \mathrm{~min}$, and the response of NCD-o toward $\mathrm{Ag}^{+}$was balanced within $6 \mathrm{~h}$.

\subsection{Fluorescence detection of $\mathrm{Fe}^{3+}$ and $\mathrm{Ag}^{+}$}

Considering that different concentrations of $\mathrm{Fe}^{3+}$ and $\mathrm{Ag}^{+}$could result in different levels of fluorescence quenching of as-prepared NCDs, this study tested the capability of NCD-m and NCD-o to detect $\mathrm{Fe}^{3+}$ and $\mathrm{Ag}^{+}$respectively.

The findings revealed that fluorescence intensity of as-prepared NCDs gradually decreased with an increase of tests-related metal ions concentration from $0 \mu \mathrm{M}$ to 1000 
$\mu \mathrm{M}$ as shown in Fig. 5a and b. Stern-Volmer equation was used to calculate fluorescence quenching. Notably, the plot of Relative Fluorescence Intensity $\left(F_{0} / F-1\right)$ against the concentration of test-related metal ions did not fit a linear Stern-Volmer equation in their entire concentration ranges. Additionally, Fig. 5c shows that there was a good linear relationship between $F_{0} / F-1$ of NCD-m and the concentration of Fe ${ }^{3+}$ within the range of $0.5-20 \mu \mathrm{M}$ with correlation coefficient $\left(R^{2}\right)$ of 0.9861 . The linear equation was fitted as $F_{0} / F-1=0.007 c+0.026(c$ representing the concentration of $\mathrm{Fe}^{3+}$ ) and limit of detection (LOD) was calculated to be $0.25 \mu \mathrm{M}$ based on three times the standard deviation rule $(\mathrm{LOD}=3 \mathrm{Sd} / \mathrm{s})$. Moreover, Fig. $5 \mathrm{~d}$ highlights that there was a good linear relationship between $F_{0} / F-1$ of NCD-o and the concentration of $\mathrm{Ag}^{+}$within the range of $5-125 \mu \mathrm{M}$ with $R^{2}$ of 0.9936 . The linear equation was fitted as $F_{0} / F-1=0.002 c+0.070\left(c\right.$ representing the concentration of $\left.\mathrm{Ag}^{+}\right)$and LOD was calculated to be $0.5 \mu \mathrm{M}$ based on three times the standard deviation rule ( $\mathrm{LOD}=3 \mathrm{Sd} / \mathrm{s})$. A comparison between the proposed methods based on as-prepared NCDs with the previously reported methods based on other CDs are listed in Table S1 and S2. The comparison suggested that the proposed methods for detection of $\mathrm{Fe}^{3+}$ and $\mathrm{Ag}{ }^{+}$were comparable or even better than those previously reported in literatures.

Given that as-prepared NCDs might be applied for detection of $\mathrm{Fe}^{3+}$ and $\mathrm{Ag}^{+}$in real samples, tap water samples were spiked with $\mathrm{Fe}^{3+} / \mathrm{Ag}^{+}$at different concentrations without any pre-treatment. Afterwards, the spiked samples were analyzed by the proposed methods based on as-prepared NCDs. Table 1 and 2 shows that recoveries from the spiked $\mathrm{Fe}^{3+}$ samples were in the range of 96.0-111.0\% with Relative Significant Difference (RSD) of 2.8-4.2\% and recoveries of the spiked $\mathrm{Ag}^{+}$samples were in the range of $96.6-106.0 \%$ with RSD of $2.1-4.5 \%$, This result suggested that NCD-m and NCD-o could be employed as the promising fluorescence sensors for quantitative detection of $\mathrm{Fe}^{3+}$ and $\mathrm{Ag}^{+}$in real water samples, respectively.

\subsection{Possible mechanism of fluorescence quenching}

Fluorescence of CDs can be generally quenched by dynamic or static quenching. 
These two quenching can be theoretically described by Stern-Volmer equation by ground-state complex formation model [27]: $F_{0} / F-1=K_{s v} c$ where $F_{0}$ and $F$ are fluorescence intensity before and after quencher addition, respectively. $K_{s v}$ is Stern-Volmer constant, and $c$ is the concentration of quencher. In this study, there were good linear relationships between Relative Fluorescence Intensity $\left(F_{0} / F-1\right)$ of as-prepared NCDs and the concentration of $\mathrm{Fe}^{3+} / \mathrm{Ag}^{+}$(Fig. 5c and d), indicating that quenching mechanism was dynamic or static quenching. Combined with FT-IR results that there were hydroxyl, carboxyl and amine groups on the surface of NCD-m, it was able to infer that NCD-m could form stable complex with $\mathrm{Fe}^{3+}$ through these functional groups, resulting in fluorescence quenching due to photo-induced electron or energy transfer and high selectivity of NCD-m to $\mathrm{Fe}^{3+}$ [38,39]. Moreover, the mechanism by which $\mathrm{Ag}^{+}$quenched fluorescence of NCD-o was also dynamic or static quenching $[40,41]$. To further understand this kind of fluorescence quenching mechanism, fluorescence lifetime experiments were performed. As shown in Fig. S4, fluorescence lifetime of NCD-m and NCD-o barely changed after they were reacted with $\mathrm{Fe}^{3+}$ and $\mathrm{Ag}^{+}$respectively. This suggested that the mechanism by which tests-related metal ions quenched fluorescence of asprepared NCDs could be attributed to static quenching. In detail, static quenching occurred when the fluorescent material formed a complex in the ground state with the quencher. Fluorescent quenching behavior involved the transfer of electrons from the excited state of as-prepared NCDs to the unfilled orbital of tests-related metal ions, leading to a nonradiative electron transfer process [42].

\subsection{Fluorescence detection of $\mathrm{AA}$}

Most of current methods for detecting AA based on CDs are "on-off-on" strategies where fluorescence of CDs is first quenched by $\mathrm{Fe}^{3+}$ then recovered from the reduction of $\mathrm{Fe}^{3+}$ to $\mathrm{Fe}^{2+}$ in the presence of AA [43-46]. But Fig. S5b suggests that fluorescence of NCD-m quenched by $\mathrm{Fe}^{3+}(500 \mu \mathrm{M})$ couldn't be recovered significantly even when the concentration of AA was up to $1000 \mu \mathrm{M}$. Additionally, the concentrations of AA 
were not positively correlated with fluorescence intensity of NCD-m when using "onoff-on" methods. Fig. S5a shows a speculation as to the cause of this unsatisfactory result. $\mathrm{Fe}^{3+}$ first bound to functional groups on the surface of NCD-m, which might cause them to inadequately react with AA. Therefore, "on-off" method was used as an alternative in this work (Fig. S5c). $\mathrm{Fe}^{3+}(500 \mu \mathrm{M})$ first reacted with AA at various concentrations. NCD-m $(0.2 \mathrm{mg} / \mathrm{mL})$ were then added into $\mathrm{Fe}^{3+}+$ AA for fluorescence measuring. As shown in Fig. S5d, there was a good positive correlation between the concentrations of AA and fluorescence intensity of NCD-m. Moreover, most fluorescence of NCD-m was retained when the concentration of AA was up to $500 \mu \mathrm{M}$. Obviously, the critical step of AA detection based on NCD-m was to ensure sufficient reaction between $\mathrm{Fe}^{3+}$ and $\mathrm{AA}$.

Given that fluorescence of NCD-m was quenched by approximately $55.6 \%$ in the presence of $\mathrm{Fe}^{3+}(500 \mu \mathrm{M})$ and the continuous increase in the concentration of $\mathrm{Fe}^{3+}$ was not able to significantly change fluorescence of NCD-m, Fe $^{3+}(500 \mu \mathrm{M})$ was chosen to react with AA at different concentrations (Fig. 5a). Thereafter, NCD-m (0.2 $\mathrm{mg} / \mathrm{mL}$ ) were added into $\mathrm{Fe}^{3+}+\mathrm{AA}$ and emission spectra were recorded at $\mathrm{Ex}=445 \mathrm{~nm}$. Fig. 6a indicates that fluorescence intensity of $\mathrm{Fe}^{3+}+\mathrm{AA}+\mathrm{NCD}-\mathrm{m}$ gradually increased with an increase in AA concentration from $0 \mu \mathrm{M}$ to $850 \mu \mathrm{M}$. In addition, the plot of Relative Fluorescence Intensity $\left(F / F_{0}\right)$ against the concentration of AA did not exhibit a linear correlation in the entire concentrations range. However, Fig. $6 \mathrm{~b}$ shows that there was a good linear relationship between $F / F_{0}$ and the concentration of AA within the range of $15-250 \mu \mathrm{M}$ with $R^{2}$ of 0.9855 . The linear equation was fitted as $F / F_{0}=0.002$ $c+0.472$ ( $c$ representing the concentration of AA). LOD was calculated to be $5 \mu \mathrm{M}$ based on three times the standard deviation rule $(\mathrm{LOD}=3 \mathrm{Sd} / \mathrm{s})$. According to the above results, NCD-m had a potential as fluorescence sensor in detection of AA.

In order to study the selectivity of NCD-m toward AA, this study selected 15 analytes including $\mathrm{Na}^{+}, \mathrm{K}^{+}, \mathrm{Ca}^{2+}$, Glu, Fru, Suc, Chol, BSA, Lys, Trp, Tyr, Cys, TA, CA, and GSH at a concentration of $500 \mu \mathrm{M}$ and observed the changes in fluorescent intensity after NCD-m were added into analyte $+\mathrm{Fe}^{3+}$ solution. The result (Fig. 7) 
revealed that cations $\left(\mathrm{Na}^{+}, \mathrm{K}^{+}, \mathrm{Ca}^{2+}\right)$, carbohydrates (Glu, Fru, Suc), amino acids (Lys, Trp, Tyr), Chol and BSA had ignorable reducibility of $\mathrm{Fe}^{3+}$ to $\mathrm{Fe}^{2+}$, which made most fluorescence of NCD-m to be quenched by $\mathrm{Fe}^{3+}$. Additionally, the chemical structures of AA, Cys, TA, CA and GSH contained reducing groups such as carboxyl and thiol[47], which results in the striking conversion of $\mathrm{Fe}^{3+}$ to $\mathrm{Fe}^{2+}$. Due to the different reducibility of these reductants, fluorescence of NCD-m was preserved to varying degrees. Therefore, Cys, TA, and CA have some interference since they are usually used as reducing agents. In particular, GSH, a well-known reducing agent, has better reducibility of $\mathrm{Fe}^{3+}$ to $\mathrm{Fe}^{2+}$ compared to AA. This phenomenon was previously employed in designing fluorescence sensors for GSH detection [48-50].

A comparison between the proposed method based on NCD-m with the previously reported methods based on other CDs are listed in Table S3, which suggests that the proposed method for detections of AA was comparable or even better than those previously reported in literatures.

Practical application of NCD-m for detection of AA in real samples including VC tablets and orange juice were carried out using a VC assay kit for comparison. The samples were pretreated as indicated in section 2.5. and spiked with AA at different concentrations. Fluorescence intensity of $\mathrm{Fe}^{3+}(500 \mu \mathrm{M})+$ real samples + NCD-m $(0.2$ $\mathrm{mg} / \mathrm{mL}$ ) was recorded at $445 \mathrm{~nm}$ (Fig. 8a). The concentrations of AA were then calculated using the linear equation (Fig. 8b). It was shown that the data detected using NCD-m was comparable to that calculated from the instructions compared to that detected using VC assay kit.

Moreover, Table 3 indicates that when NCD-m were used to analyze the spiked samples, recoveries from the spiked VC tablet samples ranged between 92.6-106.5\% with RSD of 2.6-3.8\%. On the other hand, recoveries from the spiked orange juice samples ranged between $98.2-108.5 \%$ with RSD of 2.7-4.5\%. Therefore, NCD-m displayed an acceptable precision of AA detection in real samples.

\subsection{Bacteria imaging}


To evaluate whether fluorescence sensor based on NCD-m was applicable to bacterial field, E. coli DH5 $\alpha$ were used as a model to explore the possibility of using greenemitting NCD-m for bacteria imaging. Firstly, E. coli bacteria were incubated with NCD-m solution $(0.2 \mathrm{mg} / \mathrm{mL})$ at $37^{\circ} \mathrm{C}$ for $12 \mathrm{~h}$. Fluorescent signal in bacteria was then confirmed by confocal fluorescence microscope. Bright green fluorescence in $E$. coli bacteria and the uniform morphology of E. coli bacteria were observed in Fig. 9, which indicated high quantum yield of NCD-m and high vitro cellular uptake of NCD-m by E. coli bacteria.

\section{Conclusions}

This study used a hydrothermal method to synthesize $\mathrm{Fe}^{3+}$-sensitive NCD-m and Ag ${ }^{+}$-sensitive NCD-o from soluble starch as carbon source and two isomers as nitrogen dopants. These as-prepared NCDs had the potential as fluorescence sensors to detection of $\mathrm{Fe}^{3+}$ and $\mathrm{Ag}^{+}$in aqueous solution. This is because NCD-m and NCD-o were selective toward $\mathrm{Fe}^{3+}$ and $\mathrm{Ag}^{+}$in aqueous solutions with fluorescence "on-off" mode, respectively. Additionally, a good linear relationship was observed between Relative Fluorescence Intensity $\left(F_{0} / F-1\right)$ of NCD-m/NCD-o and the concentration of $\mathrm{Fe}^{3+} / \mathrm{Ag}^{+}$within the available range. This indicated that as-prepared NCDs are able to be used for qualitative and quantitative detection of $\mathrm{Fe}^{3+}$ and $\mathrm{Ag}^{+}$. Besides, $\mathrm{Fe}$ ${ }^{2+}$ which resulted from the reduction of $\mathrm{Fe}^{3+}$ by ascorbic acid (AA) was not able to effectively quench fluorescence of NCD-m. This phenomenon was therefore applied in detection of AA. In addition, a good linear relationship was observed between Relative Fluorescence Intensity $\left(F / F_{0}\right)$ of NCD-m and the concentration of AA within the available range. In real samples, as-prepared NCDs showed acceptable precision in detection of $\mathrm{Fe}^{3+}, \mathrm{Ag}^{+}$and AA. Finally, NCD-m were able to be successfully taken by E. coli DH5 $\alpha$ bacteria and used for fluorescence imaging. Therefore, the sensors based on NCD-m and NCD-o, which utilized the economical materials, extremely simple preparation and "on-off" fluorescence strategy, provided the simple methods for multi-component $\left(\mathrm{Fe}^{3+}, \mathrm{Ag}^{+}\right.$and $\left.\mathrm{AA}\right)$ detection in real 
samples and bacteria imaging. 


\section{Author Declarations}

\section{Funding}

This study was funded by the National Natural Science Foundation of China (No.81902168).

\section{Competing interests}

The authors declare that they have no competing interests.

\section{Ethics approval and consent to participate}

Not applicable. This research did not involve clinical trials and animal experiments which were related to humans and animals as the experimental subjects. Currently, our institutions only require employees to get approval from the ethics committee before carrying out the above two kinds of experiments.

\section{Consent for publication}

Not applicable.

\section{Availability of data and materials}

All data generated or analyzed during this study are included in this published article and its supplementary materials.

\section{Code availability}

Not applicable

\section{Authors' contributions}

Yuanyuan Hu conceived and designed the study. Jun Luo conducted the literature search. Yuanyuan $\mathrm{Hu}$ and Wenxuan Ji performed the related experiments. Yuanyuan Hu, Wenxuan Ji, Jinjuan Qiao, Heng Li, Yun Zhang, and Jun Luo were involved in the analysis and interpretation of data. Yuanyuan Hu and Jun Luo drafted the manuscript. The study was supervised by Jinjuan Qiao, Heng Li and Yun Zhang. All authors read and approved the final manuscript. 


\section{References}

1. De Acha N, Elosua C, Corres JM, Arregui FJ (2019) Fluorescent Sensors for the Detection of Heavy Metal Ions in Aqueous Media. Sensors 19:599. https://doi.org/10.3390/s19030599

2. Chowdhury S, Rooj B, Dutta A, Mandal U (2018) Review on Recent Advances in Metal Ions Sensing Using Different Fluorescent Probes. Journal of Fluorescence 28:999-1021.

https://doi.org/10.1007/s10895-018-2263-y

3. Park S-H, Kwon N, Lee J-H, Yoon J, Shin I (2020) Synthetic ratiometric fluorescent probes for detection of ions. Chemical Society Reviews 49:143-179. https://doi.org/10.1039/C9CS00243J

4. Wu P, Zhao T, Wang S, Hou X (2014) Semicondutor quantum dots-based metal ion probes. Nanoscale 6:43-64. https://doi.org/10.1039/C3NR04628A

5. Li J, Zhu J-J, Xu K (2014) Fluorescent metal nanoclusters: From synthesis to applications. TrAC Trends in Analytical Chemistry 58:90-98. https://doi.org/10.1016/j.trac.2014.02.011

6. Karmakar A, Samanta P, Dutta S, Ghosh SK (2019) Fluorescent "Turn-on" Sensing Based on MetalOrganic Frameworks (MOFs). Chemistry-an Asian Journal 14:4506-4519.

https://doi.org/10.1002/asia.201901168

7. Lim SY, Shen W, Gao Z (2015) Carbon quantum dots and their applications. Chemical Society Reviews 44:362-381. https://doi.org/10.1039/c4cs00269e

8. Li X, Zhao Z, Pan C (2016) Ionic liquid-assisted electrochemical exfoliation of carbon dots of different size for fluorescent imaging of bacteria by tuning the water fraction in electrolyte.

Mikrochimica Acta 183:2525-2532. https://doi.org/10.1007/s00604-016-1877-5

9. Zhang X, Jiang M, Niu N, Chen Z, Li S (2018) Natural-Product-Derived Carbon Dots: From Natural Products to Functional Materials. ChemSusChem 11:11-24. https://doi.org/10.1002/cssc.201701847 10. Luo PG, Sahu S, Yang S-T, Sonkar SK, Wang J, Wang H, LeCroy GE, Cao L, Sun Y-P (2013) Carbon "quantum" dots for optical bioimaging. Journal of Materials Chemistry B 1:2116-2127. https://doi.org/10.1039/c3tb00018d

11. Zhu S, Zhao X, Song Y, Lu S, Yang B (2016) Beyond bottom-up carbon nanodots: Citric-acid derived organic molecules. Nano Today 11:128-132. https://doi.org/10.1016/j.nantod.2015.09.002 12. Miao S, Liang K, Zhu J, Yang B, Zhao D, Kong B (2020) Hetero-atom-doped carbon dots: Doping strategies, properties and applications. Nano Today 33:100879. 
https://doi.org/10.1016/j.nantod.2020.100879

13. Wang W, Wang B, Embrechts H, Damm C, Cadranel A, Strauss V, Distaso M, Hinterberger V, Guldi DM, Peukert W (2017) Shedding light on the effective fluorophore structure of high fluorescence quantum yield carbon nanodots. RSC Advances 7:24771-24780. https://doi.org/10.1039/C7RA04421F 14. Wang N, Chai H, Dong X, Zhou Q, Zhu L (2018) Detection of Fe(III)EDTA by using photoluminescent carbon dot with the aid of $\mathrm{F}(-)$ ion. Food Chemistry 258:51-58. https://doi.org/10.1016/j.foodchem.2018.03.050

15. Rooj B, Dutta A, Islam S, Mandal U (2018) Green Synthesized Carbon Quantum Dots from Polianthes tuberose L. Petals for Copper (II) and Iron (II) Detection. Journal of Fluorescence 28:12611267. https://doi.org/10.1007/s10895-018-2292-6

16. Omer KM, Tofiq DI, Hassan AQ (2018) Solvothermal synthesis of phosphorus and nitrogen doped carbon quantum dots as a fluorescent probe for iron(III). Mikrochimica Acta 185:466.

https://doi.org/10.1007/s00604-018-3002-4

17. Liu Y, Xue H, Liu J, Wang Q, Wang L (2018) Carbon quantum dot-based fluorometric nitrite assay by exploiting the oxidation of iron(II) to iron(III). Mikrochimica Acta $185: 129$.

https://doi.org/10.1007/s00604-018-2668-y

18. Lv P, Yao Y, Zhou H, Zhang J, Pang Z, Ao K, Cai Y, Wei Q (2017) Synthesis of novel nitrogendoped carbon dots for highly selective detection of iron ion. Nanotechnology 28:165502.

https://doi.org/10.1088/1361-6528/aa6320

19. Wang C, Huang Y, Jiang K, Humphrey MG, Zhang C (2016) Dual-emitting quantum dot/carbon nanodot-based nanoprobe for selective and sensitive detection of Fe(3+) in cells. Analyst 141:44884494. https://doi.org/10.1039/c6an00605a

20. Hamishehkar H, Ghasemzadeh B, Naseri A, Salehi R, Rasoulzadeh F (2015) Carbon dots preparation as a fluorescent sensing platform for highly efficient detection of Fe(III) ions in biological systems. Spectrochimica acta Part A, Molecular and Biomolecular Spectroscopy 150:934-939.

https://doi.org/10.1016/j.saa.2015.06.061

21. Zhang J, Yang H, Pan S, Liu H, Hu X (2021) A novel “off-on-off” fluorescent-nanoprobe based on B, $\mathrm{N}$ co-doped carbon dots and $\mathrm{MnO}_{2}$ nanosheets for sensitive detection of $\mathrm{GSH}$ and $\mathrm{Ag}(+)$.

Spectrochimica Acta Part A: Molecular and Biomolecular Spectroscopy 244:118831.

https://doi.org/10.1016/j.saa.2020.118831 
22. Dang DK, Sundaram C, Ngo Y-LT, Chung JS, Kim EJ, Hur SH (2018) One pot solid-state synthesis of highly fluorescent $\mathrm{N}$ and $\mathrm{S}$ co-doped carbon dots and its use as fluorescent probe for $\mathrm{Ag}(+)$ detection in aqueous solution. Sensors and Actuators B: Chemical 255:3284-3291.

$\underline{\text { https://doi.org/10.1016/j.snb.2017.09.155 }}$

23. Huang S, Yang E, Yao J, Liu Y, Xiao Q (2018) Red emission nitrogen, boron, sulfur co-doped carbon dots for "on-off-on" fluorescent mode detection of $\mathrm{Ag}(+)$ ions and 1-cysteine in complex biological fluids and living cells. Analytica Chimica Acta 1035:192-202.

https://doi.org/10.1016/j.aca.2018.06.051

24. Ren G, Zhang Q, Li S, Fu S, Chai F, Wang C, Qu F (2017) One pot synthesis of highly fluorescent $\mathrm{N}$ doped C-dots and used as fluorescent probe detection for $\mathrm{Hg}(2+)$ and $\mathrm{Ag}(+)$ in aqueous solution. Sensors and Actuators B: Chemical 243:244-253. https://doi.org/10.1016/j.snb.2016.11.149

25. Ma X, Lin S, Dang Y, Dai Y, Zhang X, Xia F (2019) Carbon dots as an "on-off-on" fluorescent probe for detection of $\mathrm{Cu}(\mathrm{II})$ ion, ascorbic acid, and acid phosphatase. Analytical and Bioanalytical Chemistry. https://doi.org/10.1007/s00216-019-02038-z

26. Gong X, Liu Y, Yang Z, Shuang S, Zhang Z, Dong C (2017) An "on-off-on" fluorescent nanoprobe for recognition of chromium(VI) and ascorbic acid based on phosphorus/nitrogen dual-doped carbon quantum dot. Analytica Chimica Acta 968:85-96. https://doi.org/10.1016/j.aca.2017.02.038

27. Lu W, Qin X, Liu S, Chang G, Zhang Y, Luo Y, Asiri AM, Al-Youbi AO, Sun X (2012) Economical, Green Synthesis of Fluorescent Carbon Nanoparticles and Their Use as Probes for Sensitive and Selective Detection of Mercury(II) Ions. Analytical Chemistry 84:5351-5357.

$\underline{\text { https://doi.org/10.1021/ac3007939 }}$

28. Lu J, Yang J-x, Wang J, Lim A, Wang S, Loh KP (2009) One-Pot Synthesis of Fluorescent Carbon Nanoribbons, Nanoparticles, and Graphene by the Exfoliation of Graphite in Ionic Liquids. ACS Nano 3:2367-2375. https://doi.org/10.1021/nn900546b

29. Martindale BCM, Hutton GAM, Caputo CA, Reisner E (2015) Solar Hydrogen Production Using Carbon Quantum Dots and a Molecular Nickel Catalyst. Journal of the American Chemical Society 137:6018-6025. https://doi.org/10.1021/jacs.5b01650

30. Vikneswaran R, Ramesh S, Yahya R (2014) Green synthesized carbon nanodots as a fluorescent probe for selective and sensitive detection of iron(III) ions. Materials Letters 136:179-182. 
31. Liu Y, Li W, Wu P, Ma C, Wu X, Xu M, Luo S, Xu Z, Liu S (2019) Hydrothermal synthesis of nitrogen and boron co-doped carbon quantum dots for application in acetone and dopamine sensors and multicolor cellular imaging. Sensors and Actuators B: Chemical 281:34-43.

https://doi.org/10.1016/j.snb.2018.10.075

32. Wang J, Peng F, Lu Y, Zhong Y, Wang S, Xu M, Ji X, Su Y, Liao L, He Y (2015) Large-Scale Green Synthesis of Fluorescent Carbon Nanodots and Their Use in Optics Applications. Advanced Optical Materials 3:103-111. https://doi.org/10.1002/adom.201400307

33. Ding H, Yu S-B, Wei J-S, Xiong H-M (2016) Full-Color Light-Emitting Carbon Dots with a Surface-State-Controlled Luminescence Mechanism. Acs Nano 10:484-491.

https://doi.org/10.1021/acsnano.5b05406

34. Lu S, Xiao G, Sui L, Feng T, Yong X, Zhu S, Li B, Liu Z, Zou B, Jin M, Tse JS, Yan H, Yang B (2017) Piezochromic Carbon Dots with Two-photon Fluorescence. Angewandte Chemie-International Edition 56:6187-6191. https://doi.org/10.1002/anie.201700757

35. Hu M, Yang Y, Gu X, Hu Y, Huang J, Wang C (2014) One-pot synthesis of photoluminescent carbon nanodots by carbonization of cyclodextrin and their application in $\mathrm{Ag}(+)$ detection. $\mathrm{RSC}$ Advances 4:62446-62452. https://doi.org/10.1039/C4RA11491D

36. Yuan YH, Liu ZX, Li RS, Zou HY, Lin M, Liu H, Huang CZ (2016) Synthesis of nitrogen-doping carbon dots with different photoluminescence properties by controlling the surface states. Nanoscale 8:6770-6776. https://doi.org/10.1039/C6NR00402D

37. Liu W, Li C, Sun X, Pan W, Yu G, Wang J (2017) Highly crystalline carbon dots from fresh tomato: UV emission and quantum confinement. Nanotechnology 28:485705. https://doi.org/10.1088/1361$\underline{6528 / \mathrm{aa} 900 \mathrm{~b}}$

38. Deng Z, Liu C, Jin Y, Pu J, Wang B, Chen J (2019) High quantum yield blue- and orange-emitting carbon dots: one-step microwave synthesis and applications as fluorescent films and in fingerprint and cellular imaging. Analyst 144:4569-4574. https://doi.org/10.1039/C9AN00672A

39. Li C, Liu W, Ren Y, Sun X, Pan W, Wang J (2017) The selectivity of the carboxylate groups terminated carbon dots switched by buffer solutions for the detection of multi-metal ions. Sensors and Actuators B: Chemical 240:941-948. https://doi.org/10.1016/j.snb.2016.09.068

40. Guo Y, Wang Z, Shao H, Jiang X (2013) Hydrothermal synthesis of highly fluorescent carbon nanoparticles from sodium citrate and their use for the detection of mercury ions. Carbon 52:583-589. 
https://doi.org/10.1016/j.carbon.2012.10.028

41. Ju J, Chen W (2014) Synthesis of highly fluorescent nitrogen-doped graphene quantum dots for sensitive, label-free detection of Fe (III) in aqueous media. Biosensors \& Bioelectronics 58:219-225. https://doi.org/10.1016/j.bios.2014.02.061

42. Meng A, Xu Q, Zhao K, Li Z, Liang J, Li Q (2018) A highly selective and sensitive "on-off-on" fluorescent probe for detecting $\mathrm{Hg}(\mathrm{II})$ based on $\mathrm{Au} / \mathrm{N}$-doped carbon quantum dots. Sensors and Actuators B-Chemical 255:657-665. https://doi.org/10.1016/j.snb.2017.08.028

43. Wang M, Wan Y, Zhang K, Fu Q, Wang L, Zeng J, Xia Z, Gao D (2019) Green synthesis of carbon dots using the flowers of Osmanthus fragrans (Thunb.) Lour. as precursors: application in $\mathrm{Fe}(3+)$ and ascorbic acid determination and cell imaging. Analytical and Bioanalytical Chemistry 411:2715-2727. https://doi.org/10.1007/s00216-019-01712-6

44. Li J, Tang K, Yu J, Wang H, Tu M, Wang X (2019) Nitrogen and chlorine co-doped carbon dots as probe for sensing and imaging in biological samples. Royal Society Open Science 6:181557.

https://doi.org/10.1098/rsos.181557

45. Chen K, Qing W, Hu W, Lu M, Wang Y, Liu X (2019) On-off-on fluorescent carbon dots from waste tea: Their properties, antioxidant and selective detection of $\mathrm{CrO}_{4}(2-), \mathrm{Fe}(3+)$, ascorbic acid and L-cysteine in real samples. Spectrochimica Acta Part A: Molecular and Biomolecular Spectroscopy 213:228-234. https://doi.org/10.1016/j.saa.2019.01.066

46. Shamsipur M, Molaei K, Molaabasi F, Alipour M, Alizadeh N, Hosseinkhani S, Hosseini M (2018) Facile preparation and characterization of new green emitting carbon dots for sensitive and selective off/on detection of $\mathrm{Fe}(3+)$ ion and ascorbic acid in water and urine samples and intracellular imaging in living cells. Talanta 183:122-130. https://doi.org/10.1016/j.talanta.2018.02.042

47. Ma X, Lin S, Dang Y, Dai Y, Zhang X, Xia F (2019) Carbon dots as an "on-off-on" fluorescent probe for detection of $\mathrm{Cu}(\mathrm{II})$ ion, ascorbic acid, and acid phosphatase. Analytical and Bioanalytical Chemistry 411:6645-6653. https://doi.org/10.1007/s00216-019-02038-Z

48. Huang Y, Zhou J, Feng H, Zheng J, Ma HM, Liu W, Tang C, Ao H, Zhao M, Qian Z (2016) A dualchannel fluorescent chemosensor for discriminative detection of glutathione based on functionalized carbon quantum dots. Biosensors \& Bioelectronics 86:748-755.

https://doi.org/10.1016/j.bios.2016.07.081

49. Guo Y, Yang L, Li W, Wang X, Shang Y, Li B (2016) Carbon dots doped with nitrogen and sulfur 
and loaded with copper(II) as a "turn-on" fluorescent probe for cystein, glutathione and homocysteine. Microchimica Acta 183:1409-1416. https://doi.org/10.1007/s00604-016-1779-6

50. Liao S, Huang X, Yang H, Chen X (2018) Nitrogen-doped carbon quantum dots as a fluorescent probe to detect copper ions, glutathione, and intracellular $\mathrm{pH}$. Analytical and Bioanalytical Chemistry 410:7701-7710. https://doi.org/10.1007/s00216-018-1387-x

Table 1 Detection of $\mathrm{Fe}^{3+}$ using NCD-m in real samples $(\mathrm{n}=5)$ 


\begin{tabular}{ccccc}
\hline Samples & Add $(\boldsymbol{\mu M})$ & Total found $(\boldsymbol{\mu M})$ & Recovery $(\%)$ & RSD $(\%)$ \\
\hline \multirow{3}{*}{ Tap water } & 5.0 & 4.8 & 96.0 & 3.1 \\
& 10.0 & 11.1 & 111.0 & 4.2 \\
& 15.0 & 16.3 & 108.7 & 2.8 \\
\hline
\end{tabular}

Table 2 Detection of $\mathrm{Ag}^{+}$using NCD-o in real samples $(\mathrm{n}=5)$

\begin{tabular}{ccccc}
\hline Samples & Add $(\boldsymbol{\mu M})$ & Total found $(\boldsymbol{\mu M})$ & Recovery $(\%)$ & RSD (\%) \\
\hline \multirow{2}{*}{ Tap water } & 10.0 & 10.6 & 106.0 & 2.7 \\
& 50.0 & 48.3 & 96.6 & 2.1 \\
& 100.0 & 97.6 & 97.6 & 4.5 \\
\hline
\end{tabular}

Table 3 Detection of AA using NCD-m in real samples $(n=5)$

\begin{tabular}{cccccc}
\hline \multicolumn{1}{c}{ Samples } & Found $(\boldsymbol{\mu M})$ & Add $(\boldsymbol{\mu M})$ & Total found $(\boldsymbol{\mu M})$ & Recovery $(\%)$ & RSD $(\%)$ \\
\hline \multirow{2}{*}{ VC tablets } & 98.3 & 20.0 & 119.6 & 106.5 & 3.5 \\
& 97.6 & 35.0 & 134.4 & 105.1 & 3.8 \\
& 102.3 & 50.0 & 148.6 & 92.6 & 2.6 \\
Orange juice & 48.7 & 20.0 & & & 4.5 \\
& 48.6 & 55.0 & 83.8 & 108.5 & 2.7 \\
\hline
\end{tabular}


Graphical Abstract Strategy for synthesis of nitrogen-doped carbon dots (NCDs) and a schematic for fabrication of as-prepared NCDs for detection of $\mathrm{Fe}^{3+}, \mathrm{Ag}^{+}$and ascorbic acid (AA).

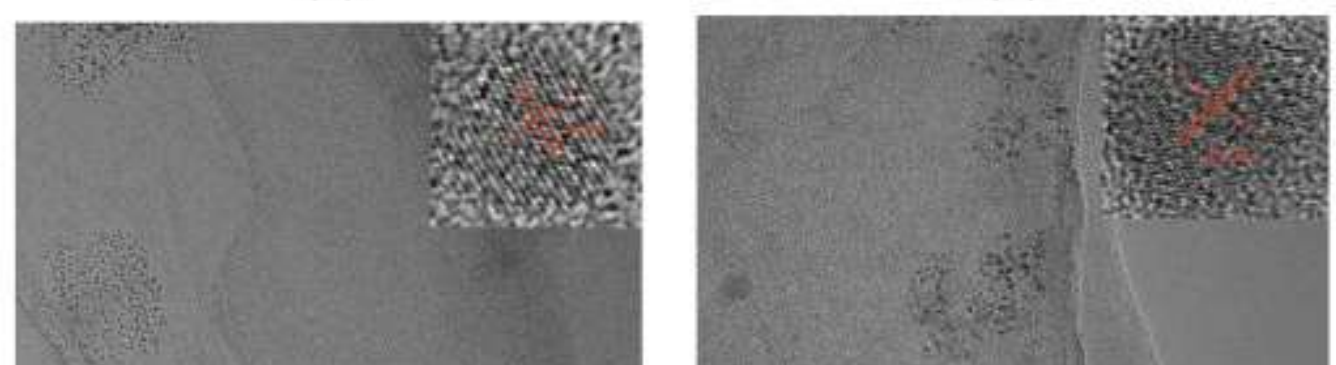


Fig. 1 (a, b) TEM images (Insets: lattice structures), (c) XRD pattern and (d) FT-IR spectra of as-prepared NCDs.

(a)

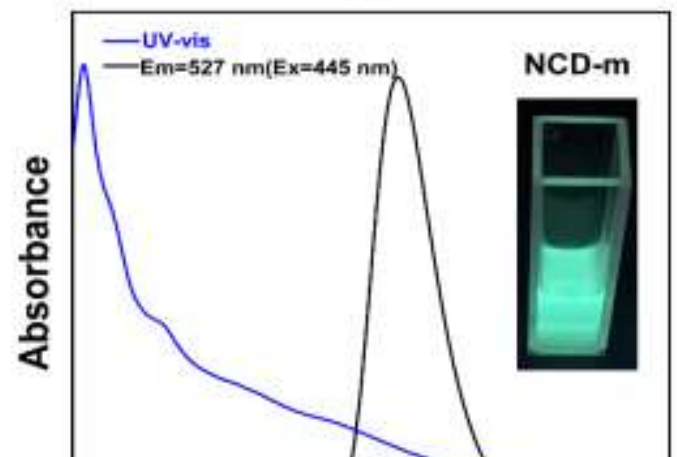

(b)

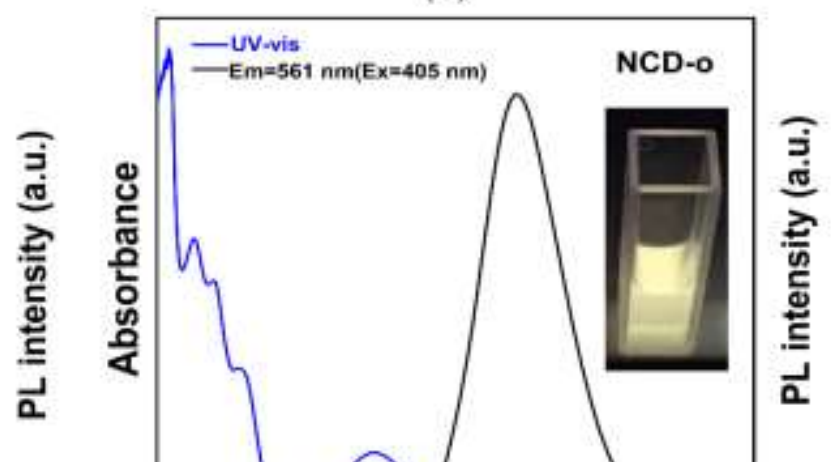


Fig. 2 (a, b) UV-visible absorption and fluorescence emission spectra of as-prepared NCDs (Insets are photographs of as-prepared NCDs aqueous solutions under $365 \mathrm{~nm}$ UV lamp).

(a)
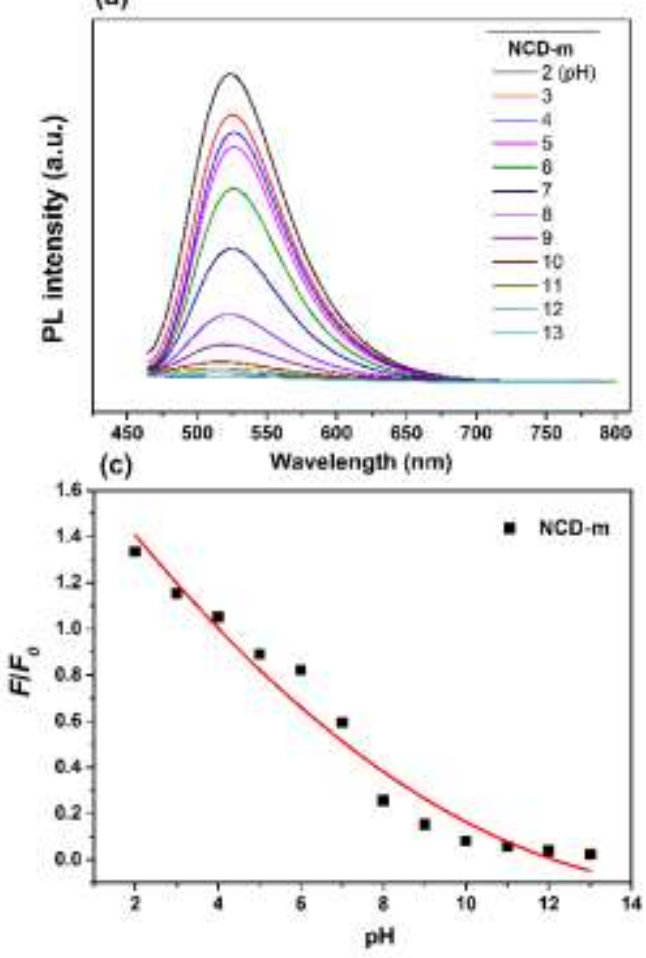

(b)
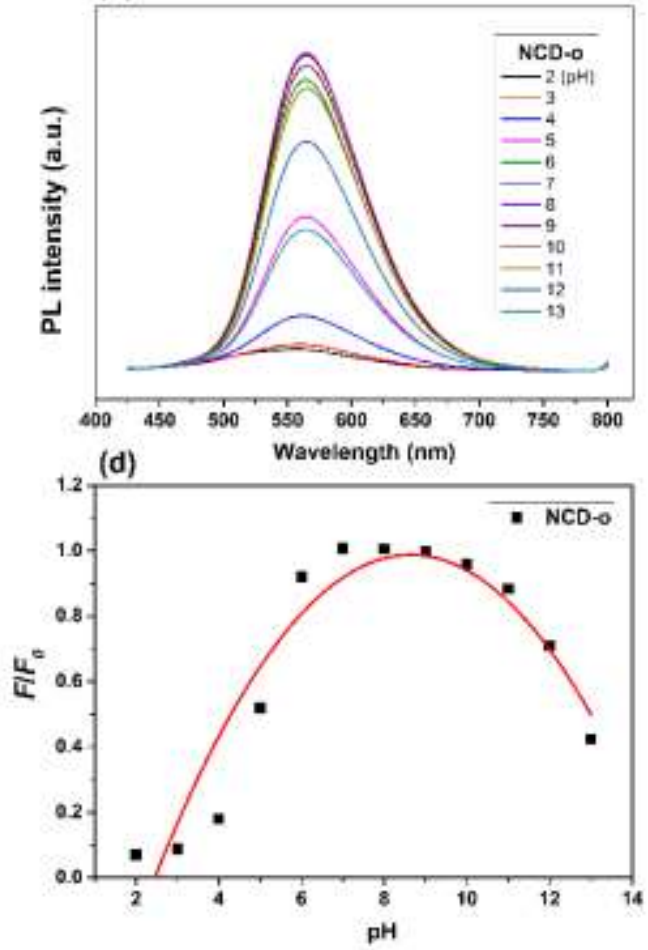

Fig. 3 Influence of $\mathrm{pH}$ change on (a, b) fluorescence emission spectra and (c, d) Relative Fluorescence Intensity of as-prepared NCDs. 


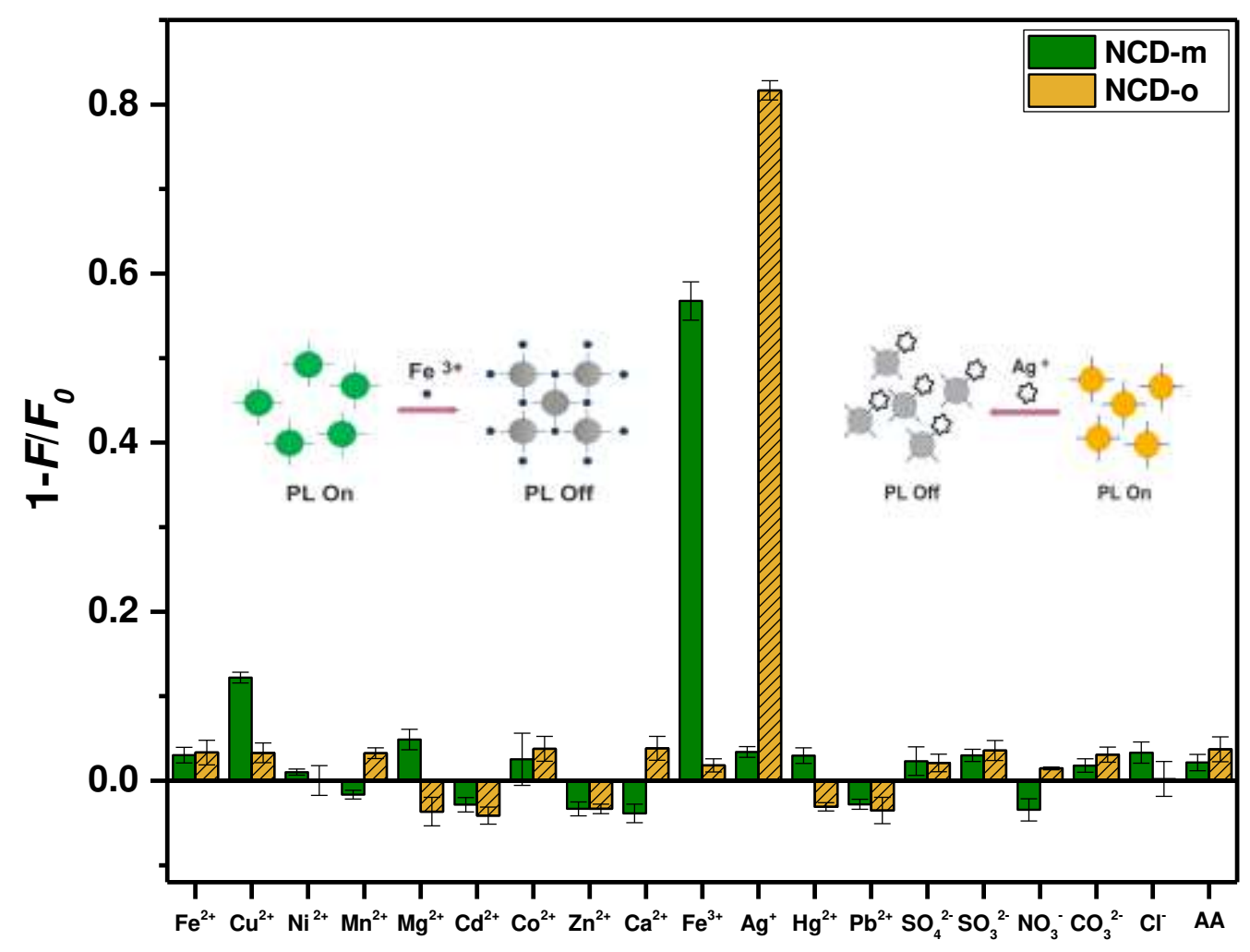

Fig. 4 Selectivity of NCD-m and NCD-o to various analytes.

(a)

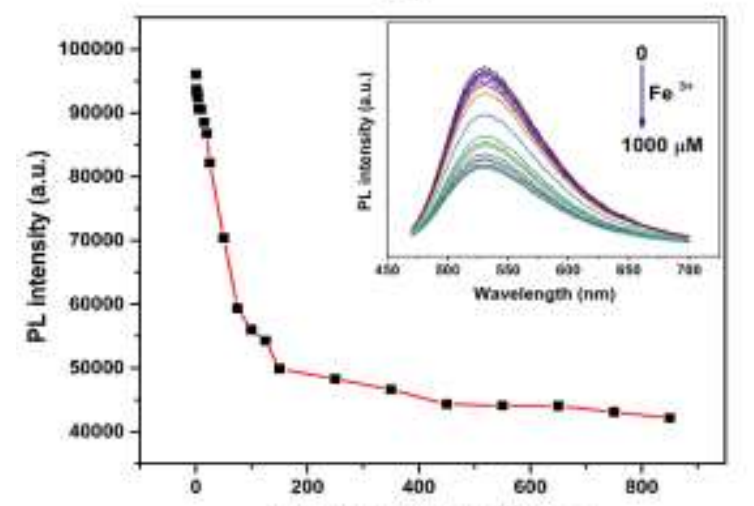

(b)

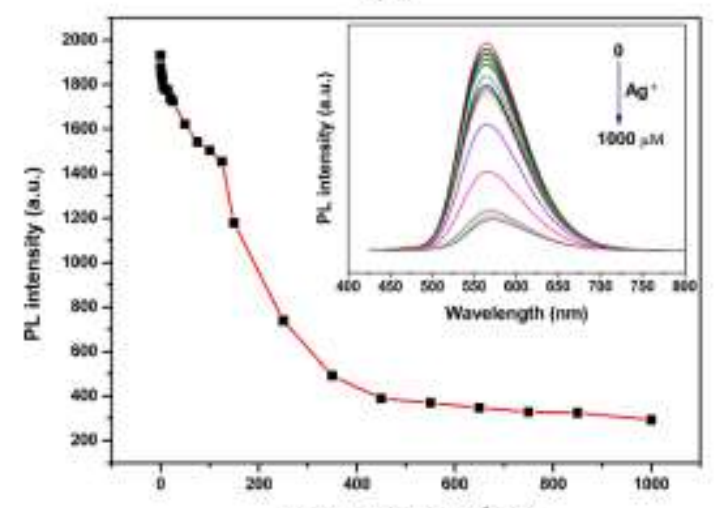


Fig. 5 Fluorescence emission spectra and intensity of (a) NCD-m $(0.2 \mathrm{mg} / \mathrm{mL})+\mathrm{Fe}^{3+}$ and (b) NCD-o $(0.2 \mathrm{mg} / \mathrm{mL})+\mathrm{Ag}^{+}$. (c) Linear relationship between Relative Fluorescence Intensity of NCD-m and the concentration of $\mathrm{Fe}^{3+}$ within the range of 0.5-20 $\mu \mathrm{M}$. (d) Linear relationship between Relative Fluorescence Intensity of NCD-o and the concentration of $\mathrm{Ag}^{+}$within the range of 5-125 $\mu \mathrm{M}$.

(a)

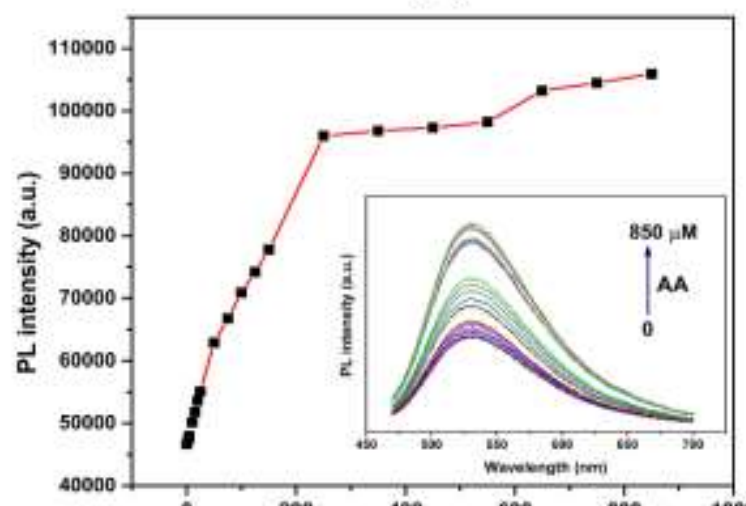

(b)

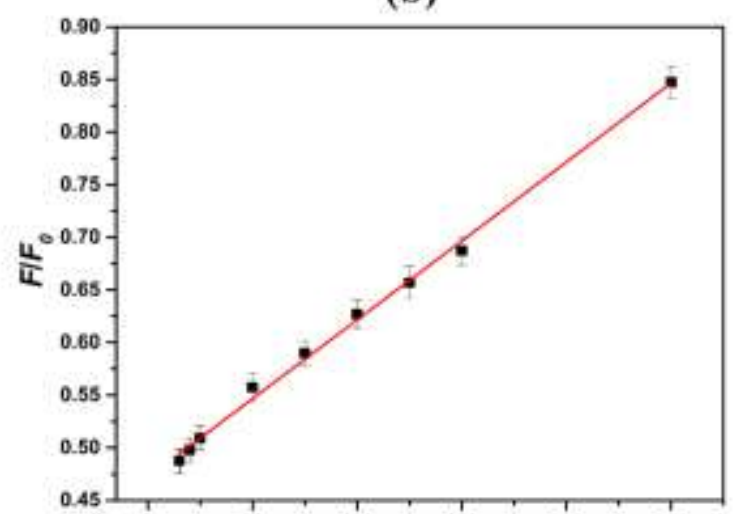


Fig. 6 (a) Fluorescence emission spectra and intensity of $\mathrm{Fe}^{3+}(0.5 \mathrm{mM})+\mathrm{AA}+\mathrm{NCD}-$ $\mathrm{m}(0.2 \mathrm{mg} / \mathrm{mL})$. (b) Linear relationship between Relative Fluorescence Intensity of NCD-m and the concentration of AA within the range of 15-250 $\mu \mathrm{M}$.

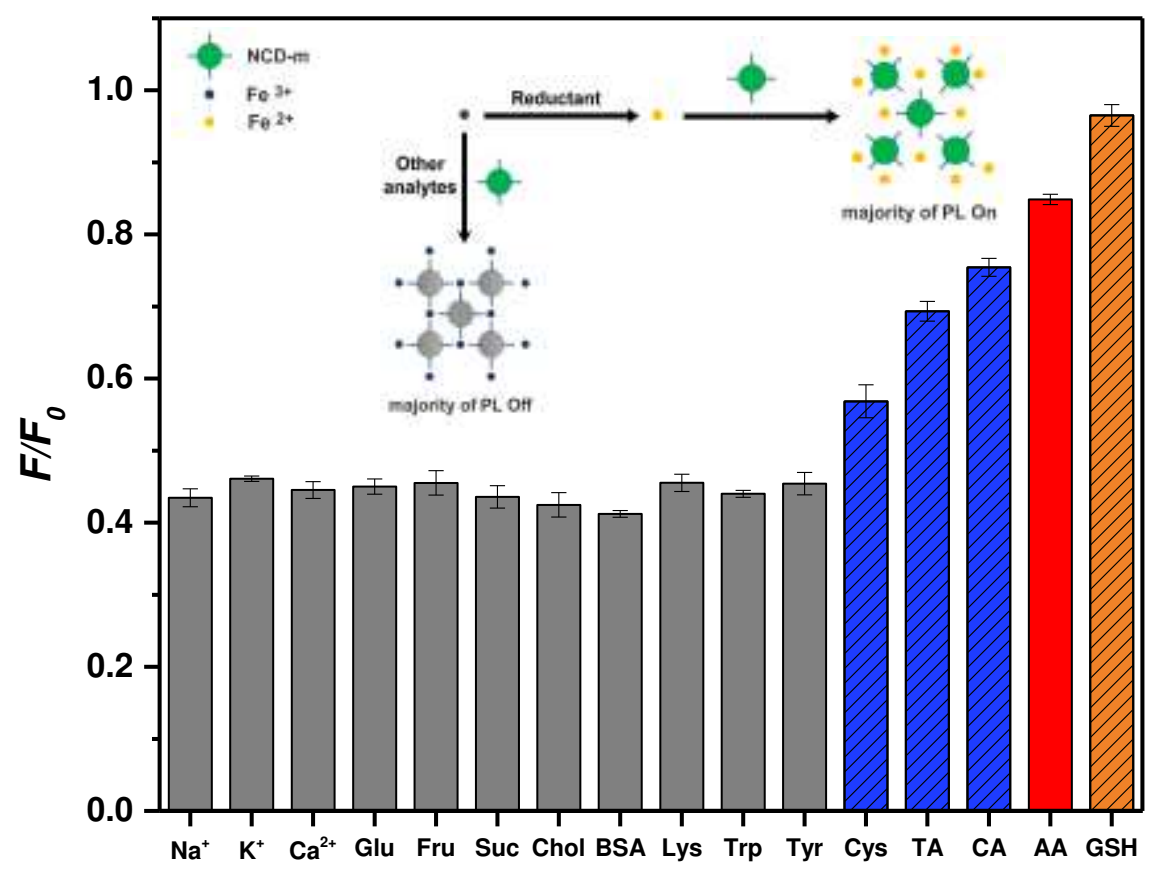

Fig. 7 Selectivity of NCD-m to various analytes.

(a)

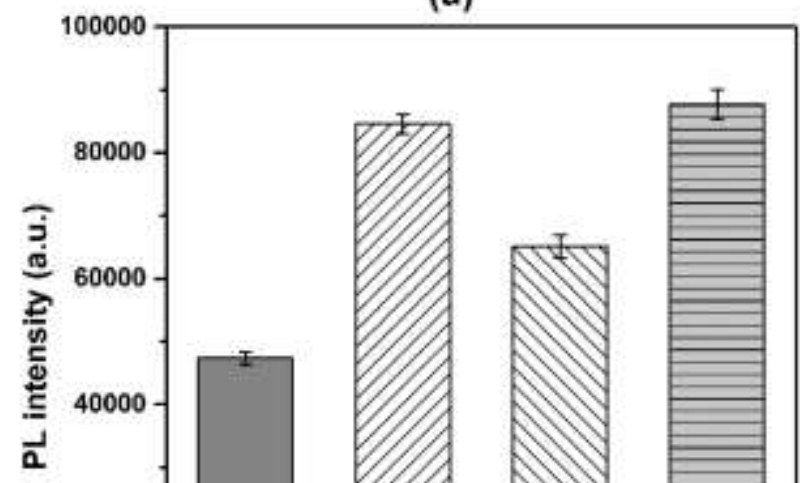

(b)

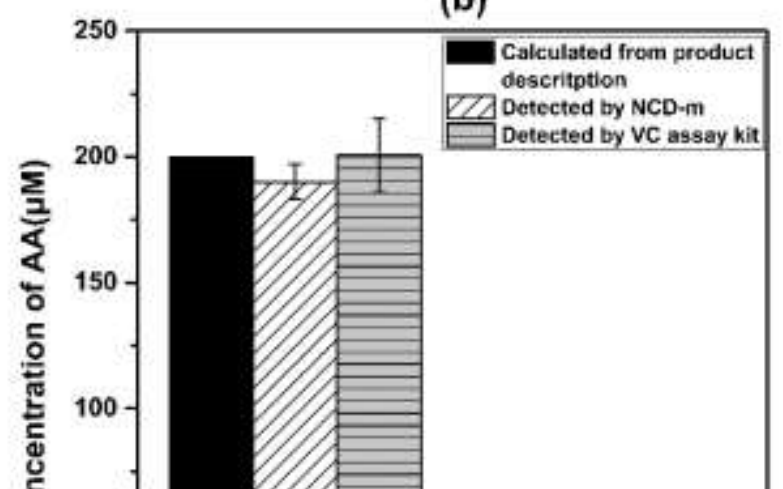


Fig. 8 (a) Fluorescence intensity of $\mathrm{Fe}^{3+}(0.5 \mathrm{mM})+$ real samples + NCD-m $(0.2$ $\mathrm{mg} / \mathrm{mL}$ ). (b) Concentration of AA calculated from product description, detected using NCD-m as sensor, and detected using VC assay kit.

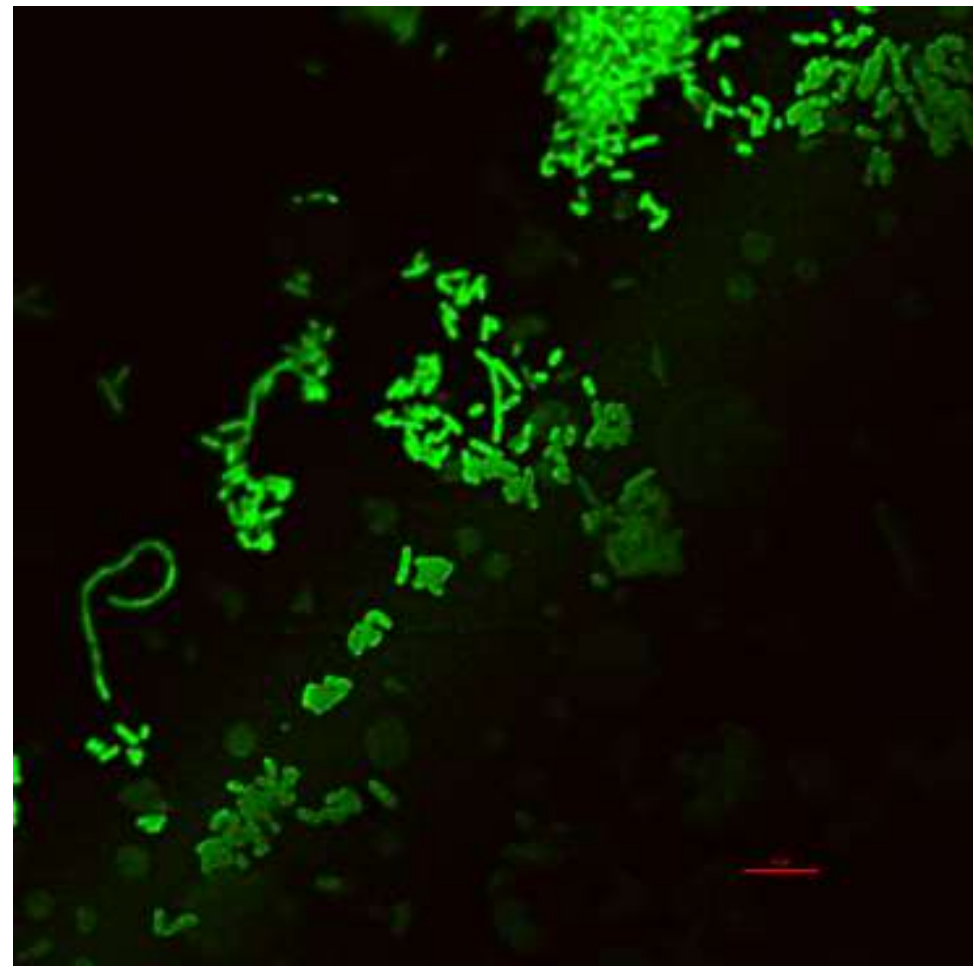

Fig. 9 Fluorescence image (magnification $60 \times$ ) of $E$. coli $\mathrm{DH} 5 \alpha$ bacteria treated with NCD-m. 
Figures

(a)

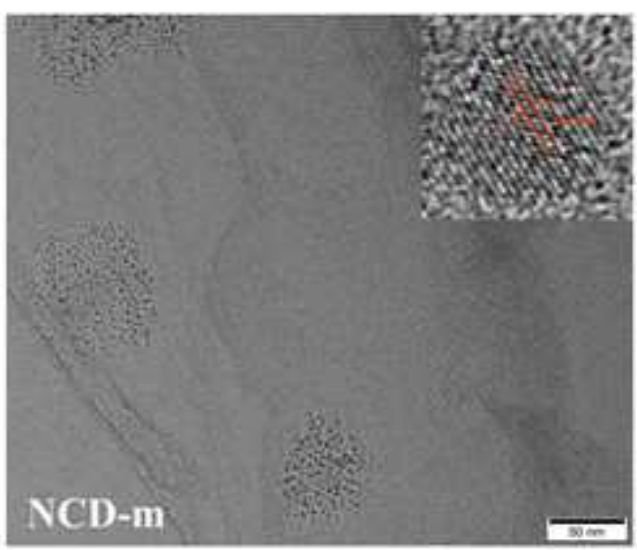

(c)

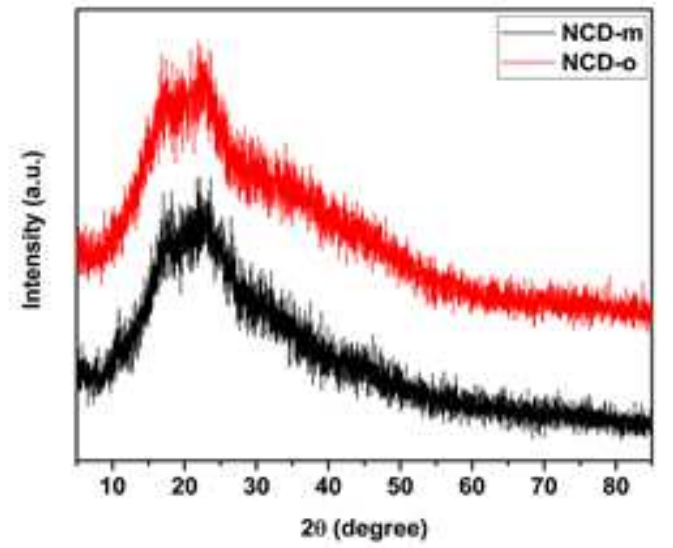

(b)

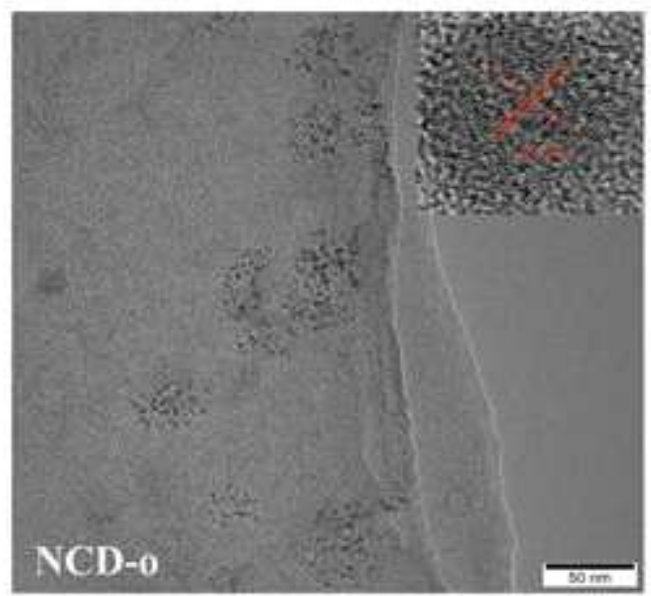

(d)

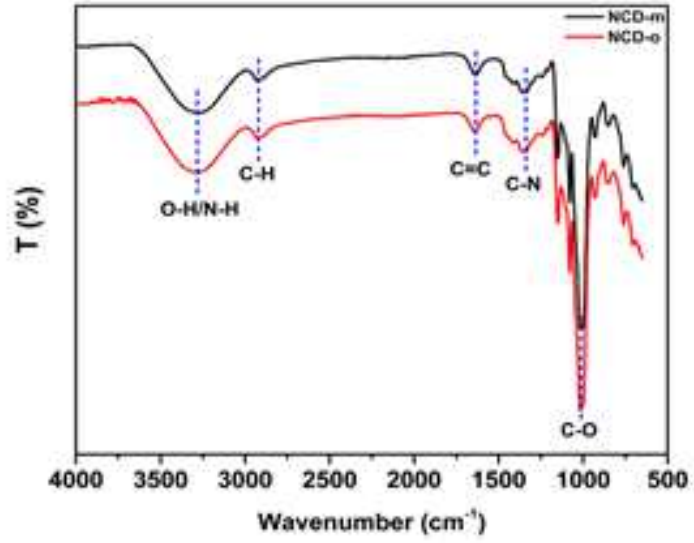

Figure 1

(a, b) TEM images (Insets: lattice structures), (c) XRD pattern and (d) FT-IR spectra of as-prepared NCDs.

(a)

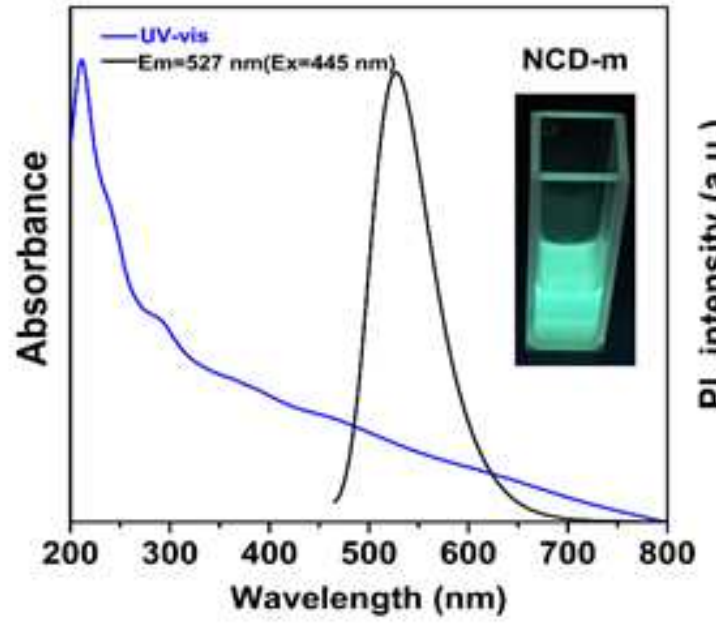

(b)

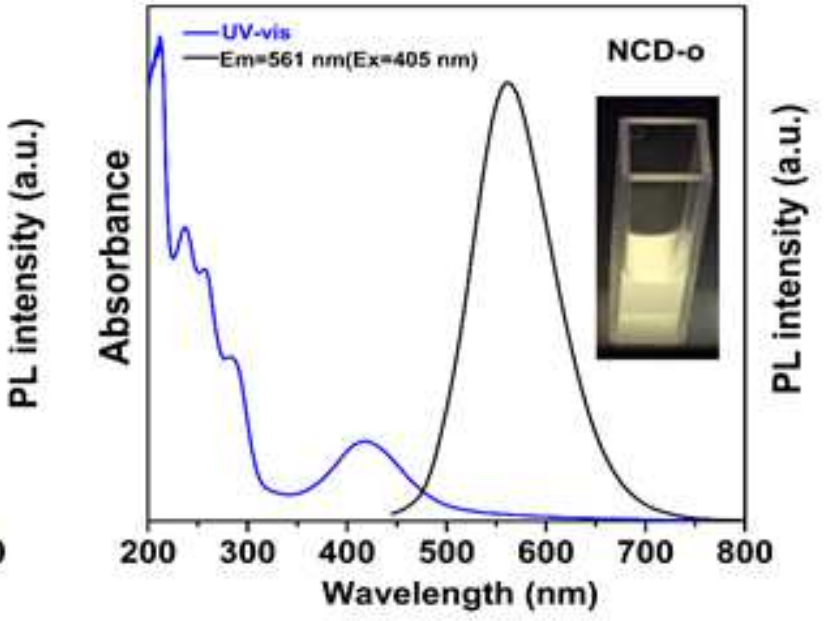


Figure 2

$(a, b)$ UV-visible absorption and fluorescence emission spectra of as-prepared NCDs (Insets are photographs of as-prepared NCDs aqueous solutions under $365 \mathrm{~nm}$ UV lamp).

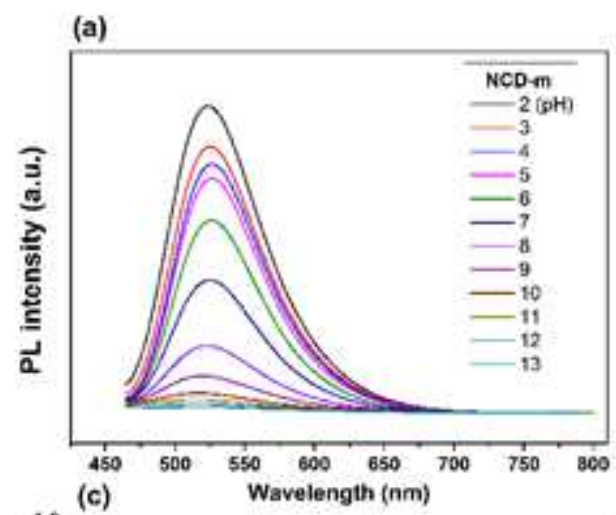

(b)
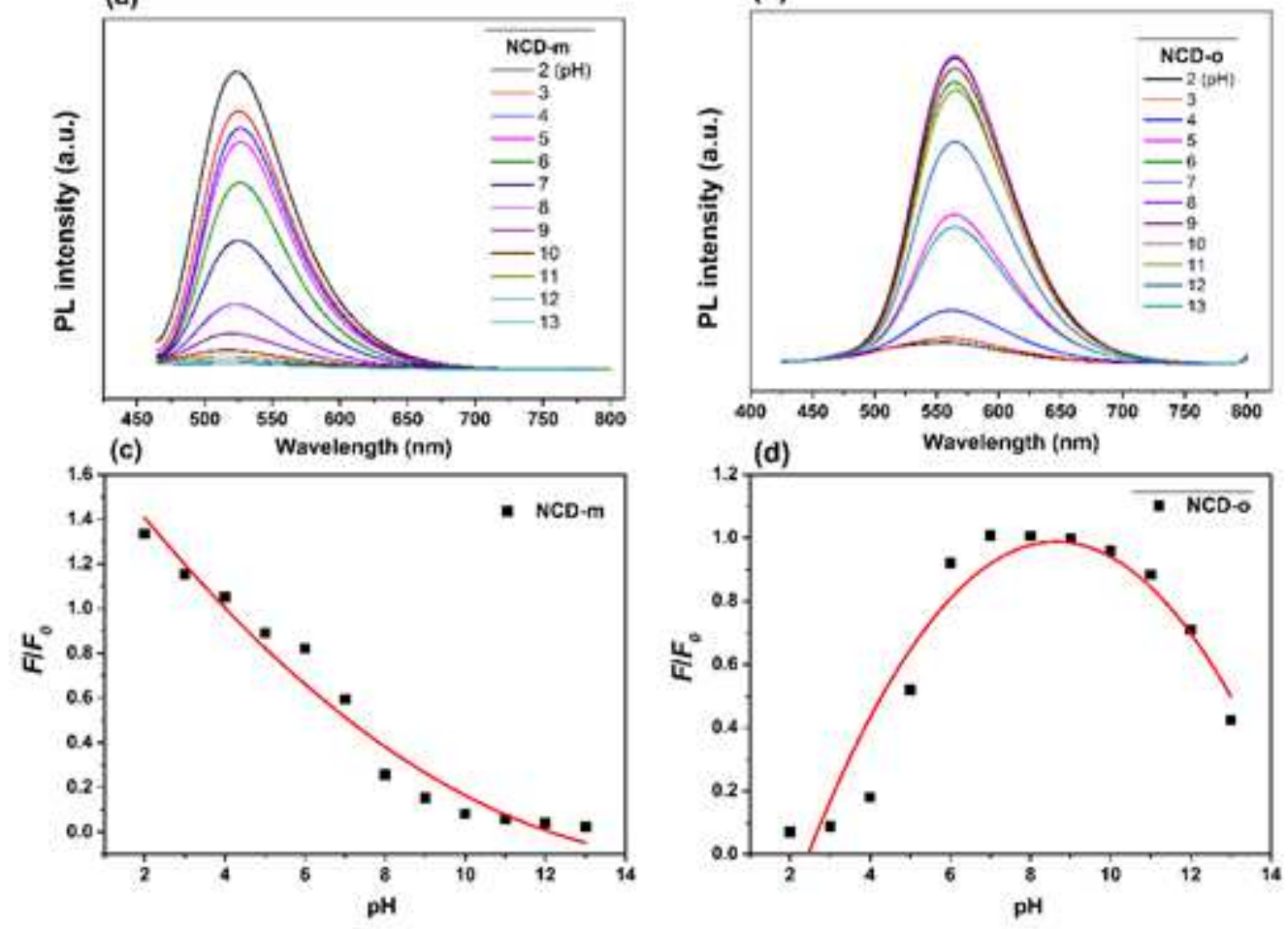

Figure 3

Influence of $\mathrm{pH}$ change on $(\mathrm{a}, \mathrm{b})$ fluorescence emission spectra and $(\mathrm{c}, \mathrm{d})$ Relative Fluorescence Intensity of as-prepared NCDs. 


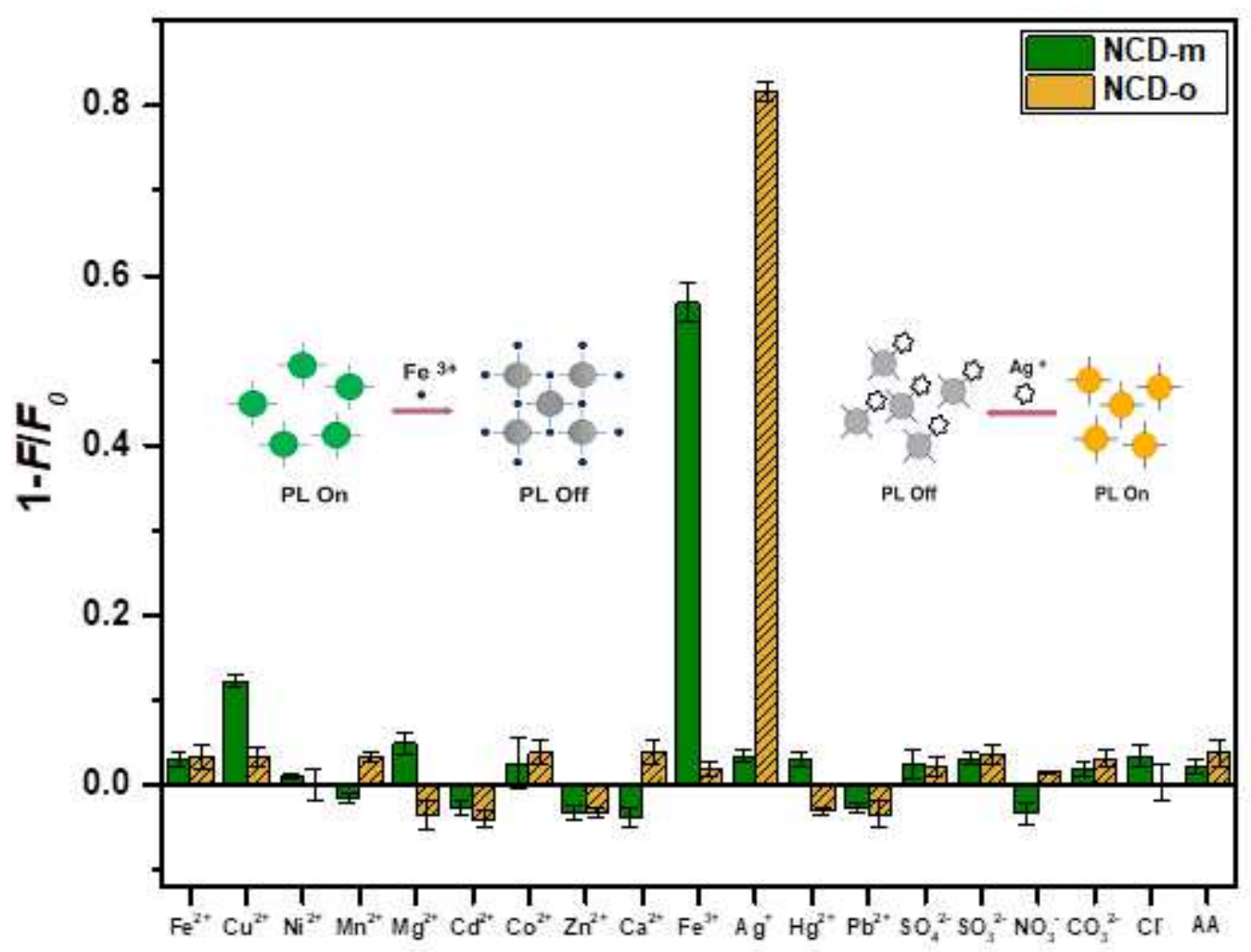

Figure 4

Selectivity of NCD-m and NCD-o to various analytes. 
(a)

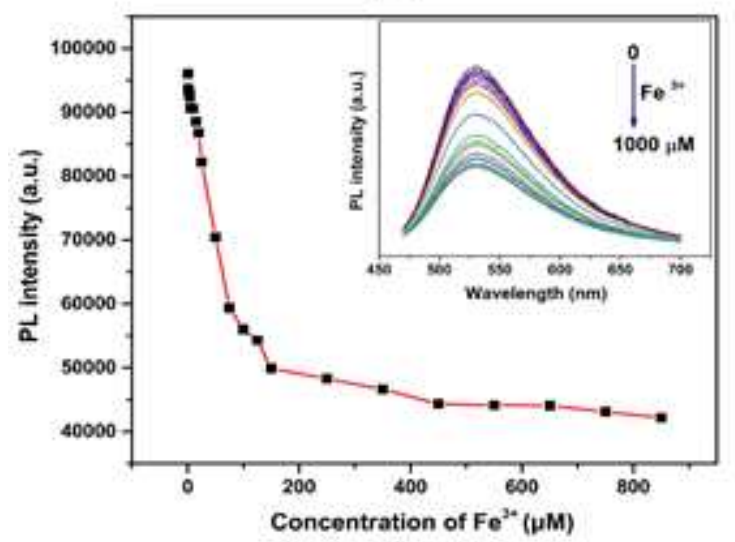

(c)

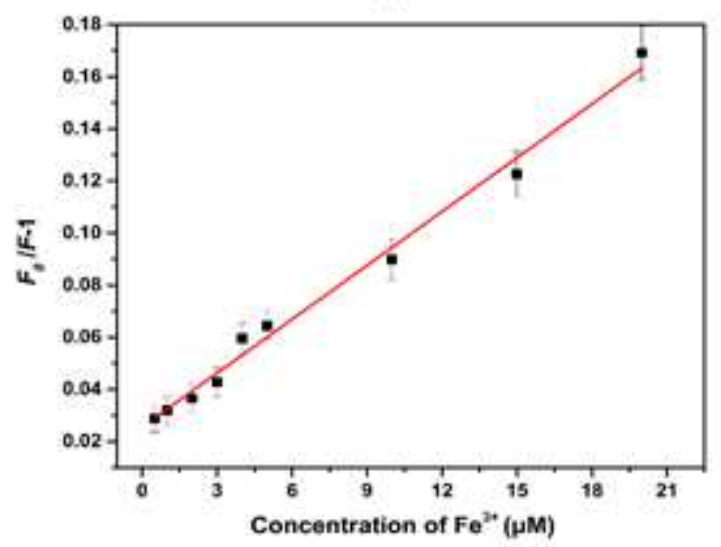

(b)

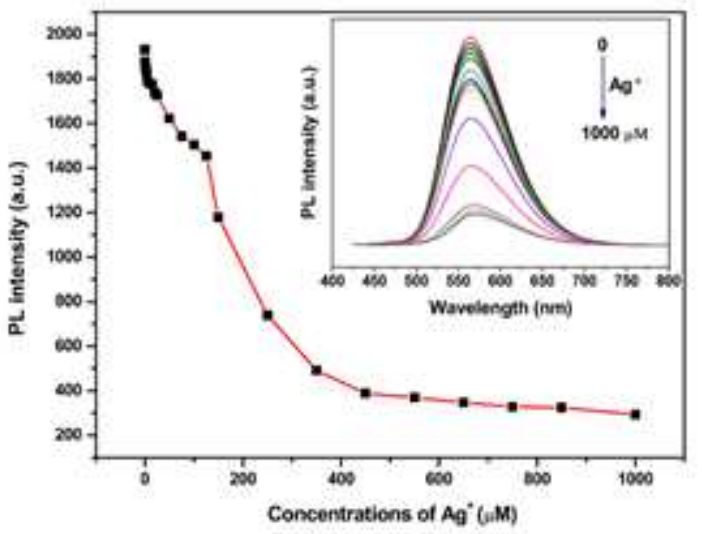

(d)

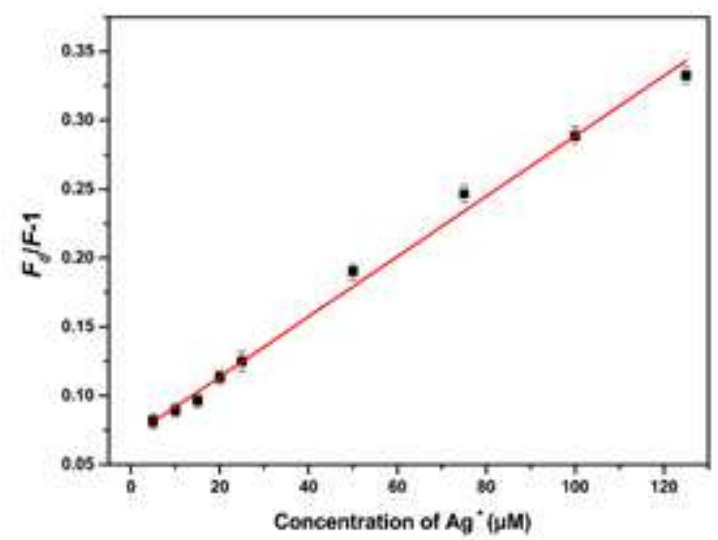

Figure 5

Fluorescence emission spectra and intensity of (a) NCD-m $(0.2 \mathrm{mg} / \mathrm{mL})+\mathrm{Fe} 3+$ and (b) NCD-o (0.2 $\mathrm{mg} / \mathrm{mL})+\mathrm{Ag}+$. (c) Linear relationship between Relative Fluorescence Intensity of NCD-m and the concentration of Fe 3+ within the range of 0.5-20 $\mu \mathrm{M}$. (d) Linear relationship between Relative Fluorescence Intensity of NCD-o and the concentration of Ag + within the range of 5-125 $\mu \mathrm{M}$.

(a)

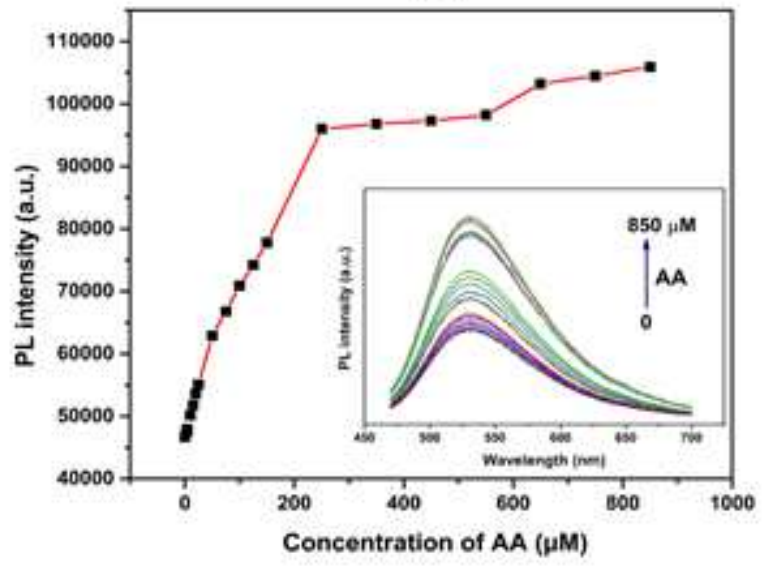

(b)

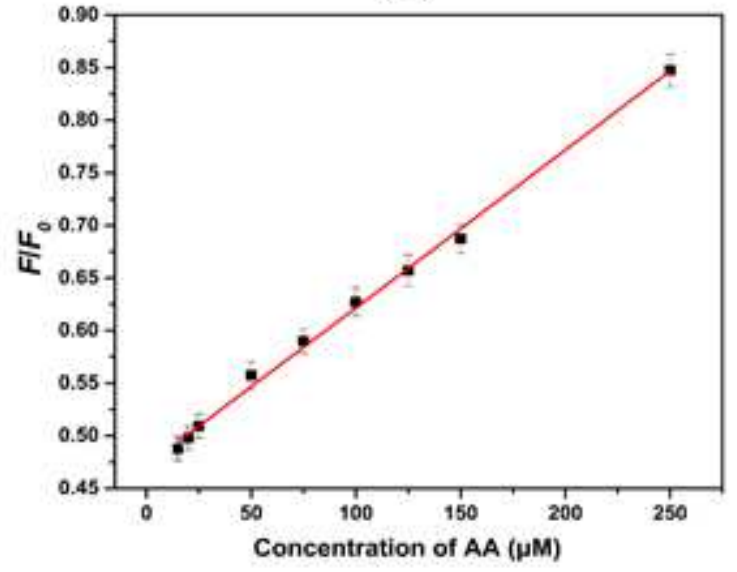

Figure 6 
(a) Fluorescence emission spectra and intensity of Fe $3+(0.5 \mathrm{mM})+\mathrm{AA}+\mathrm{NCD}-\mathrm{m}(0.2 \mathrm{mg} / \mathrm{mL})$. (b) Linear relationship between Relative Fluorescence Intensity of NCD-m and the concentration of AA within the range of $15-250 \mu \mathrm{M}$.

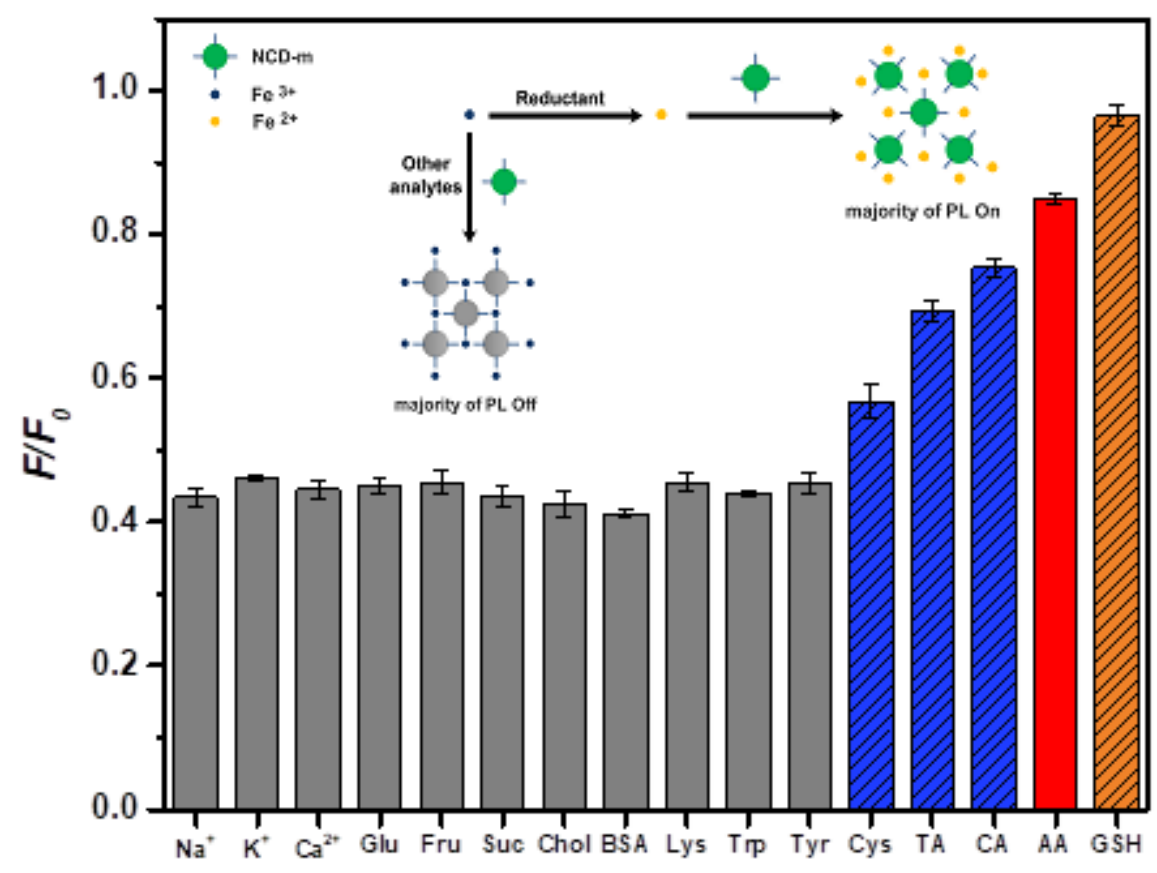

Figure 7

Selectivity of NCD-m to various analytes.

(a)

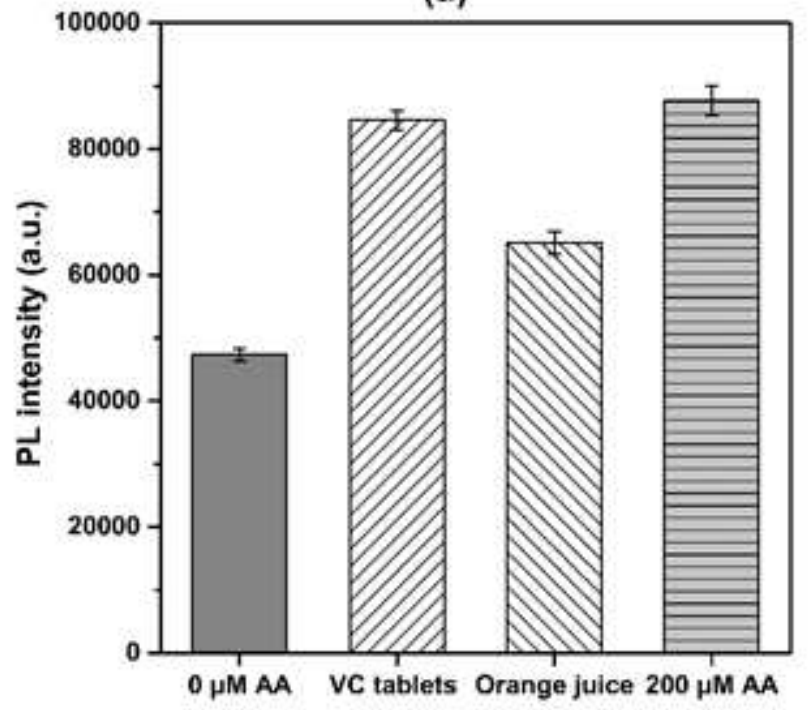

(b)

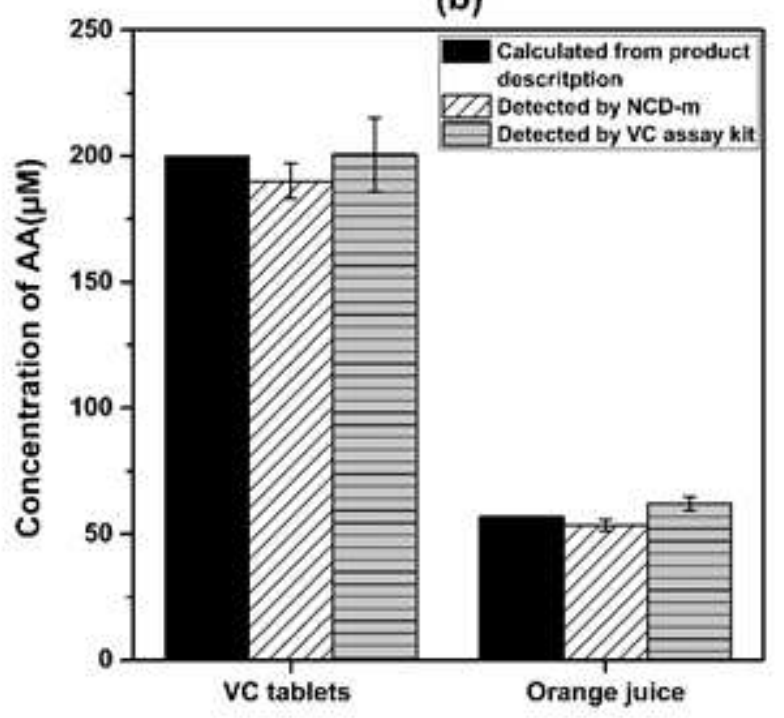

Figure 8

(a) Fluorescence intensity of Fe $3+(0.5 \mathrm{mM})+$ real samples + NCD-m $(0.2 \mathrm{mg} / \mathrm{mL})$. (b) Concentration of AA calculated from product description, detected using NCD-m as sensor, and detected using VC assay kit. 


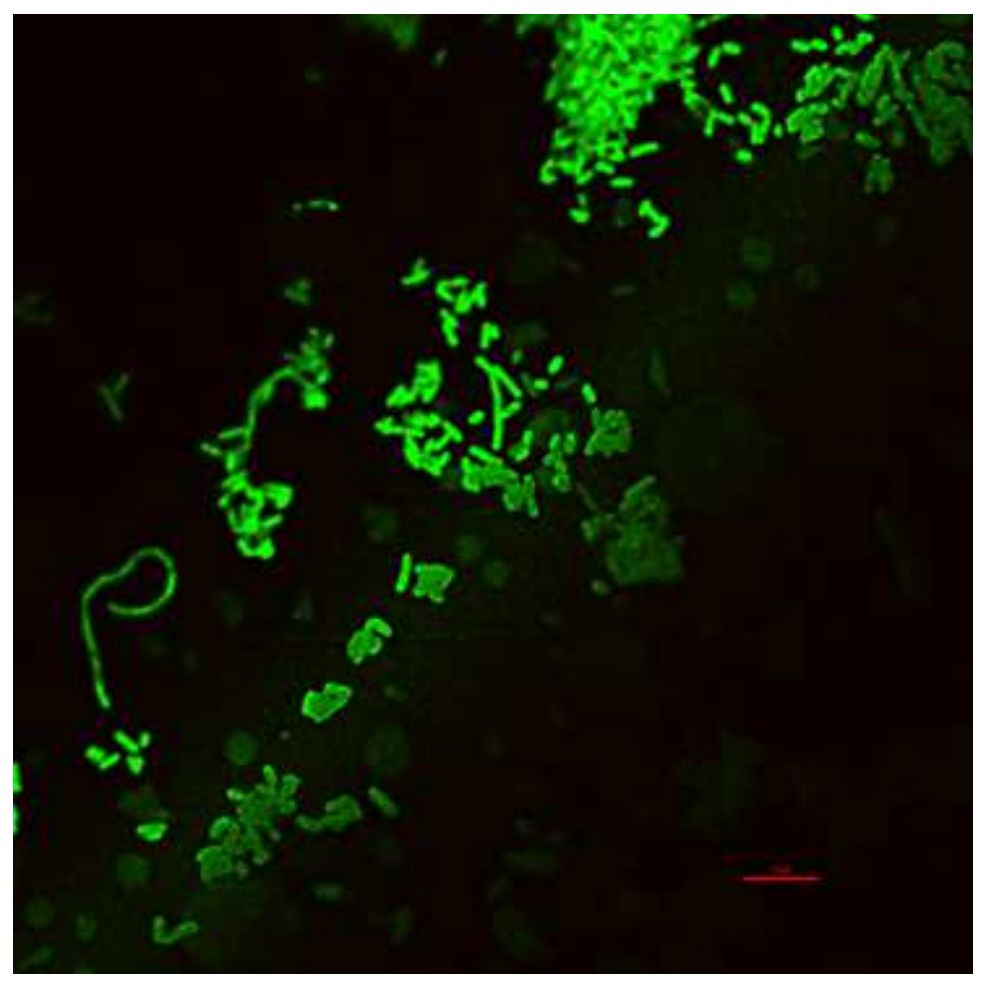

Figure 9

Fluorescence image (magnification 60x) of E. coli DH5a bacteria treated with NCD-m. 